\title{
The development of a low-carbon roadmap investment strategy to reach Science Based Targets for commercial organisations with multi-site properties
}

\author{
Alexandre N. Ayoub, Anatole Gaigneux, Niccolo Le Brun, Salvador Acha*, Nilay Shah \\ Department of Chemical Engineering, Imperial College London, London, UK
}

\begin{abstract}
N.B.: This is the ACCEPTED MANUSCRIPT version of this article. The final, published version of the article can be found at: https://doi.org/10.1016/j.buildenv.2020.107311
\end{abstract}

\begin{abstract}
The Paris Climate Agreement has motivated commercial organisations to set and work towards Science Based Targets, a realignment of greenhouse gas emissions in line with climate science. This work presents a modelling framework to develop cost-effective decarbonisation investment programs that address electricity and heat carbon emissions in organisations with multiple properties. The case study takes a set of 60 supermarkets in the UK and evaluates the techno-economic viability of installing biomethane combined heat and power engines and photovoltaic panels to make them zero carbon buildings. Simulation results from the batch of buildings offer the financial and environmental benefits at each site and generates a set of regression coefficients which are then applied into an optimisation problem. Solving the optimisation yields the decarbonisation investment strategy for the estate up to 2050; indicating the preferred sequence of investments the company needs to undertake to embark upon an effective low-carbon roadmap. A sensitivity analysis compliments the study to understand how market and policy externalities may influence roadmaps. Results suggest a CAPEX ranging from £57$£ 80$ million is required to deliver an ambitious decarbonisation plan, while OPEX and carbon savings benefits range between $£ 197$ and $£ 683$ million and $461-715 \mathrm{ktCO}_{2} \mathrm{e}$; respectively. The case study highlights that although carbon targets can be achieved by 2030, the 2050 targets are more challenging to meet; suggesting additional technologies and policies should be considered and implemented. The framework serves as a blueprint of how modelling can assist decision-makers in reducing their carbon footprint cost-effectively to reach Science Based Targets.
\end{abstract}

Keywords: Decarbonisation; Distributed energy systems, Environmental strategy; Low-carbon roadmap, Science based targets; Sustainability.

* Corresponding author. E-mail address: salvador.acha@imperial.ac.uk (Salvador Acha). 


$\begin{array}{ll}\text { Abbreviations } \\ \text { BaU } & \text { Business as Usual } \\ \text { BEIS } & \text { Business, Energy \& Industrial Strategy } \\ \text { CAPEX } & \text { Capital Expenses } \\ \text { CHP } & \text { Combined Heat and Power } \\ \mathrm{CO}_{2} \mathrm{e} & \text { Carbon dioxide equivalent } \\ \text { CPPA } & \text { Corporate power purchase agreement } \\ \text { ECA } & \text { Enhanced Capital Allowance } \\ \text { FIT } & \text { Feed In Tariffs } \\ \text { GHG } & \text { Greenhouse Gas } \\ \text { kWe } & \text { Kilo-watt electric } \\ \text { kW } & \text { Kilo-watt thermal } \\ \text { KPI } & \text { Key Performance Indicator } \\ \text { MARS } & \text { Multivariate Adaptive Regression Splines } \\ \text { MILP } & \text { Mixed Integer Linear Program } \\ \text { OPEX } & \text { Operational Expenses } \\ \text { ORC } & \text { Organic Rankine Cycle } \\ \text { PV } & \text { Photovoltaic } \\ \text { ROI } & \text { Return on Investment } \\ \text { YoY } & \text { Year on Year }\end{array}$

\section{Nomenclature}

\begin{tabular}{|c|c|c|}
\hline $\begin{array}{l}\text { Notation } \\
\text { Sets }\end{array}$ & Dependence & Description \\
\hline$t$ & - & Time period representing years 2020 to $2050 . t \in \mathbb{Z}: t \in[1,30]$ \\
\hline tech & - & Technology installed. tech $\in\left[\mathrm{PV}, \mathrm{CHP},{ }^{\prime}\right.$ dummy', ppa $]$ \\
\hline$s$ & - & Store number where half hourly data is available \\
\hline$d$ & - & Domain of regression for MARS analysis. $d \in \mathbb{Z}: \mathrm{d} \in[1,4]$ \\
\hline $\mathrm{p}$ & - & PV Panels \\
\hline \multicolumn{3}{|l|}{ Parameters } \\
\hline$S t$ & $t$ & Array of length $t$ for carbon reduction target in tonnes $\mathrm{CO}_{2} \mathrm{e}$ \\
\hline$K_{i}$ & $d$, tech, $t, s$ & Regression coefficients for OPEX and Carbon savings \\
\hline$K 0_{\text {CAPEX }}$ & tech, $t$ & Intercept of linear regression of CAPEX of each technology \\
\hline$K 1_{\text {CAPEX }}$ & tech, $t$ & Slope of linear regression of CAPEX of each technology \\
\hline Mo & tech & Array of 0 and 1 to indicate if technology is modular \\
\hline$L b$ & $d$, tech, $t, s$ & Lower bounds of domains of regression for MARS analysis \\
\hline Lt & $d$, tech, $t, s$ & Upper bounds of domains of regression for MARS analysis \\
\hline$\alpha$ & - & Factor allowing for flexibility in yearly investments $\alpha \in \mathbb{R}: \alpha \in[0,1]$ \\
\hline \multicolumn{3}{|c|}{ ositive variables } \\
\hline$Y i$ & $t$ & Total amount invested per year \\
\hline$S a_{i}$ & $t, s$ & Yearly OPEX and carbon savings after installation per store \\
\hline$x$ & tech, $t, s$ & Size of technology installed (\# panels for PV, $\mathrm{kW}$ for CHP) \\
\hline capex & $t, s$ & Investment needed to install a certain technology size \\
\hline $\mathrm{Nm}$ & $t e c h, t, s$ & Investment needed to install a CHP engine \\
\hline \multicolumn{3}{|r|}{ 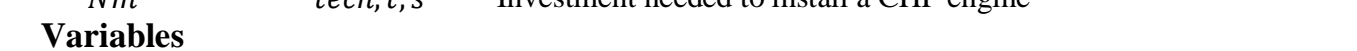 } \\
\hline$f$ & $d$, tech, $t, s$ & Objective function value \\
\hline $\mathrm{A}_{\mathrm{p}}$ & & Area for solar panels available \\
\hline$r$ & & Discount rate \\
\hline$O c$ & & Operating cost \\
\hline$P p$ & & Fixed periodic payment \\
\hline Ti & & Total investment \\
\hline$t f$ & & Tech lifetime \\
\hline$P$ & & Power \\
\hline$I r$ & & Irradiance \\
\hline eff & & Efficiency \\
\hline$N P$ & & Nominal power \\
\hline$N_{p}$ & & Number of solar panels \\
\hline$P$ & & Power output \\
\hline
\end{tabular}




$$
\begin{aligned}
& P r \\
& E d \\
& E p \\
& H p \\
& P L \\
& T d
\end{aligned}
$$

Binary variables

IO

$\mathrm{Co}_{i}$

Notation
Panel price

Electricity demand

Electricity production

Heat production

Part-load

Thermal demand

tech, $t, s \quad$ Indicate if technology is installed

$d, t, s \quad$ To calculate OPEX and carbon savings on the correct domain of regression.

$=\{O P E X, C O 2\}$ 


\section{Introduction}

In 2015, 195 countries signed the Paris Climate Agreement at COP21, aiming to limit global temperature increase to $2{ }^{\circ} \mathrm{C}$, relative to pre-industrial temperatures. This is the first-ever universal, legally binding global climate change accord aiming to strengthen countries' ability to deal with the impacts of climate change and support them in their efforts [1]. The COP21 has accelerated the transition to a low-carbon economy globally, across all economic sectors, particularly within energy intensive organisations who are becoming more transparent and meticulous in their GHG footprint reporting [2]. More than 350 companies have already committed to science-based targets, this initiative supports organisations in counteracting political short-termism by setting a glidepath towards long-term emissions reduction. Science based targets are in line with the level of decarbonisation set by climate science while future-proofing growth, as described in the Fifth Assessment Report of the Intergovernmental Panel on Climate Change (IPCC AR5) [3].

The advantages of setting ambitious environmental targets is that leading companies and governments will collaborate in developing innovation in low carbon technologies while also evaluating new policies that support their implementation [4]. Solutions from the supply-side can range from low-carbon electrification, carbon capture, bioenergy sources, and zero-carbon hydrogen. Meanwhile, important demand-side alternatives include championing energy efficiency, energy generation on-site, replacement of high-carbon materials for low-carbon materials and circular economy practices. A combination of all these solutions should ensure the competitiveness of key industries in a future where governmental policies will most likely set carbon pricing and energy efficiency standards, while achieving net zero emissions in the required timeframe set by the Paris agreement without sacrificing human and economic development.

Due to these ambitious environmental pledges, organisations face the challenge of enhancing their business intelligence and start implementing sustainable operations while simultaneously ensuring these investments adequately utilise economic resources without forsaking productivity [5].

Currently, it is common for organisations to outsource their carbon mitigation initiatives and become "green" through renewable energy Corporate Power Purchase Agreements (CPPAs) either dealing directly with producers or retailers [6]. CPPAs require organisations to commit for a lengthy period to finance these renewable projects and although there is commercial risk in these agreements some organisations have managed to sign pledges in sourcing $100 \%$ of their electricity through renewables (i.e. wind, solar, etc.) [7]. Nonetheless, green CPPAs can carry high risks as guaranteeing the supply of power at a reasonable cost might prove difficult and deter organisations away from them [8]. As an alternative to green CPPAs, if organisations can allow it in their premises producing energy on-site through distributed technologies is another viable option to decarbonise operations in energy intensive buildings, that is if the economic case can be justified [9].

If commercial organisations with multi-site properties could substantially reduce their GHG footprint by addressing their energy related carbon emissions via distributed energy systems, how would their technology investment programme look like? This problem is at the centre of this work and a technoeconomic optimisation modelling framework is proposed to try and answer this challenging question. The model allows the end-user to calculate the optimal level of investment and expected financial returns their efforts to decarbonise will entail over time. Furthermore, the model indicates the preferred sequence of investments to undertake on a site by site basis while determining the carbon savings each investment brings. Therefore, the model outputs have the capability to inform decision-makers on the preferred investment strategy for decarbonising a large portfolio of buildings and getting closer towards reaching Science Based Targets. To the best of the authors knowledge no works in the literature has tried previously to answer this question for multi-site property commercial organisations.

The research presented in this paper showcases a detailed case study of how supply-side technology investments could decarbonise the buildings of a large UK food retailer. In other words, through the case study example we attempt to illustrate how modelling can aid in creating a sound quantitative 
blueprint so private companies can decarbonise through a robust cost-effective investment program that supports their journey towards net zero carbon. Due to this context, the literature reviewed discussed next focuses on how we can achieve food retail sustainability though modelling and analysis.

The food retail industry is large and complex providing the vital service of supplying goods to society. In the UK, food retailers and its supply-chain are a major sector in the economy, projected to be worth $£ 217.7$ billion by 2024 [10]. Furthermore, the food system accounts for about $18 \%$ of total energy use and $176 \mathrm{MtCO}_{2 \mathrm{e}}$ in greenhouse gas (GHG) emissions [11]. However, it must be noted that only about $13 \%$ of the total carbon footprint from the food supply-chain is attributable to supermarkets as most of the emissions are embedded at the sourcing and consumption of products.

Food retailers are now accustomed like many other companies in the last few years to publish corporate sustainability reports detailing their environmental progress although a push towards greater transparency and detail in key metrics is still advocated [12]. The annual GHG emissions breakdown of a UK food-retail company for scopes 1 and 2 are shown in Table 1 [13]. As indirect emissions from grid electricity use is the largest contributor to total supermarket GHG emissions, this is the carbon source this work focuses on addressing.

Table 1: Annual food retail GHG emissions breakdown of a UK supermarket company.

\begin{tabular}{|c|c|}
\hline Source & Percentage of total carbon emissions \\
\hline Natural gas & $21 \%$ \\
\hline Transportation & $21 \%$ \\
\hline Refrigerants & $13 \%$ \\
\hline Electricity & $46 \%$ \\
\hline
\end{tabular}

As Table 1 illustrates, non-electricity related emissions in commercial organisations are not insignificant. To satisfy heating demand supermarkets are exploring heat recovery methods from their refrigeration systems so they can displace natural gas related emissions, although matching supply and demand is a persistent issue that requires thermal storage [14]. With regards to minimising the impact of carbon intensive refrigerants advanced performance indicators championing energy efficiency and leakage reduction is advocated [15] as well as the phasing out of HFC refrigerants by increasing the uptake of natural refrigerants [16]. Lastly, it seems decarbonising transport fleets is a more challenging endeavour, where exploring alternative fuels to diesel such as LNG or biomethane is being considered, however the refuelling infrastructure to supply low carbon fuels is a major roadblock [17]. Whatever carbon source organisations wish to mitigate, a robust and tangible sustainability plan needs to be developed.

Organisations trying to embed sustainability programmes in their operations are usually influenced by policies, reporting guidelines and stakeholder pressure and they employ low-carbon roadmaps to strategize how best to reach such environmental targets [18]. These roadmaps comprise both qualitative trend-based studies and technology deterministic studies, often operating within a 'back-casting' framework [19]. The main development stages are defining a baseline of the current state, developing a future vision and working backwards to identify appropriate actions. This method structure and attributes enables early identification and periodical review of the decisions made and their impact at critical points in time, if sustainability objectives are to be achieved [20].

Marginal Abatement Cost (MAC) curves are also used to provide insights when it comes to comparing a wide range of alternatives with regards to their cost and benefit in emissions reduction and the associated costs of such investments. MAC curves are a very intuitive visualisation of the viability of low-carbon technologies, aiding in the investment decision-making process. Though MAC curves are useful for providing preliminary insights they treat uncertainty in a limited manner, do not consider in detail the utilisation of the technologies, and lack transparency around their underlying assumptions [21]. 
Previous research includes both investigation into the factors influencing total food-retail energy use and carbon emissions, and the methods to tackle them. Spyrou et al. [22] investigated the electricity and gas demand drivers in large food retail buildings. The paper outlines the method used to create multiple linear regression models that predict energy and gas demand of multiple food retail stores based on several independent variables. Similar works used regression techniques to forecast the impact of climate change on supermarket buildings, suggesting natural gas demand will go down but electricity demand will only have minor increase [23]. While most works focus on total energy use in buildings, some publications have gone further into the energy use and characterisation of key services such as space heating $[24,25]$ and cooling [26, 27]; suggesting alternatives to reduce energy consumption. Meanwhile, Mavromatidis et al. [28] developed modelling frameworks employing machine learning methods to benchmark and evaluate energy use in food retail buildings and their key energy intensive systems. Alternatively, other works have tried to evaluate the impact building occupancy can have on driving energy demands. For instance, Howard et al. [60] suggests advanced sensing and communications can enable building management systems to adjust energy settings for services such as heating and ventilation. By understanding the fundamentals of what drives the energy use in buildings it then makes possible to research the options available to improve energy efficiency [29].

Aside from trying to analyse and reduce energy demand in buildings, a niche field of research focuses on evaluating the impact distributed energy systems producing clean sustainable energy in commercial buildings can have on the environment. The literature suggests that optimising the use of these technologies through modelling can help maximize energy efficiency and savings with regards to carbon and costs [30]. Among the options these include combined heat and power (CHP) systems and their integrated combinations with other technologies like absorption chillers, organic Rankine cycle (ORC) engines and how they can be complemented with photovoltaic (PV) solar panels, and batteries; mostly trying to address electricity, heating and cooling needs [31]. For example, Tassou and Suamir [32] analysed the techno-economic impact from integrated trigeneration systems featuring an absorption chiller system but not optimising its performance. In contrast, Cedillos at al. [33] introduced a distributed technology optimisation techno-economic model that provides decision-makers with insight on how CHP systems can benefit the performance of commercial buildings. This publication was then expanded upon by Mariaud et al. [34] by covering the impact optimal PV and battery system combinations can have on food retail distribution centres. Some other works have investigated decarbonising heat provision through biomass boilers [35]. Although much work has been done on exploring the impact of distributed energy systems in individual buildings, the application of portfolio theory to incorporate distributed systems has not been explored considerably [36].

Strategic decarbonisation literature through modelling is not abundant in the literature, however there is high-level systematic models selecting power supply options to meet reduction targets and characterise roadmap pathways. For instance, a multi-model roadmap for the European Union (EU) up to 2050 shows reaching targets is feasible with current technologies, however delaying action beyond 2030 stresses the system capabilities for decarbonisation and leads to significantly higher costs [37]. Now, when devising long-term decarbonisation strategies, extensive research into the impact of uncertainty is required to understand the trade-offs energy transitions can bring. Fais et al. [38] explored the variability in energy use and technology complementary/substitutability. Their research highlights the importance of early decarbonisation action in the presence of multiple-technology uncertainty. Meanwhile, mid-term uncertainties are portrayed as critical influencing near-term investments in energy systems up to 2030 due to the complex relationship between the flexibility of energy systems and mitigating the costs of uncertainty due to the path-dependencies caused by the long-life times of both infrastructures and generation technologies [39]. Although these works focus on strategic decarbonisation at a regional or national scale, no works in the literature seem to address low carbon roadmaps for commercial properties. Furthermore, it has been acknowledged there is a lack of clarity on how to deliver zero carbon buildings in retrofit projects, while integration of energy solutions is key [62]. Particularly, for existing buildings that require comprehensive retrofits real energy demand and economic performance data is required to properly analyse the impact any investment might have [63]. 
The most important barriers to the implementation of carbon reduction schemes include lack of resources, the risk associated with investing in emerging technologies and, the lack of adequate planning [40]. It is apparent many companies lack a strategic approach and the means required to decarbonise their operations cost-effectively. As research suggests, improving building energy use requires a careful balance between demand reduction, on-site generation, and delivering value to the investor [61]. As our literature review shows, extensive research and know-how on decarbonising individual buildings exists, but expanding this expertise and transferring across a large property portfolio remains a significant challenge. However, there is encouraging research that suggests that the more ambitious organisations are in setting carbon targets the more likely they will achieve them through cutting-edge innovation [41]. Organisations need to embed a systematic approach and analytical tools in their activities to make sure they are making sound environmental progress. For food retailers, analysing representative stores and applying the learnings to make sound assumptions across their portfolio can allow them to gain clarity and build pathways to meet ambitious carbon mitigation targets through cost-effective investments.

This paper presents a decarbonisation investment strategy in buildings by installing distributed energy systems. The strategy considers both the current market and possible future scenarios, considering variation in utility costs, capital costs and grid carbon factors. The key research question addressed is how to achieve emission reduction targets in a cost- effective manner, using multiple technologies, over a large multi-site estate. Thus, showcasing the prowess of a methodology that can facilitate decisionmakers optimise the sequence of low carbon investments so they can successfully meet ambitious environmental goals in commercial buildings; such as supermarkets. A range of technology types and sizes are considered in this work, resulting in various investment roadmaps, spanning the time period of 2020-2050. The paper focuses particularly on the installation of CHP and PV systems as they mature technologies that can have immediate impact [31], [42]. To the best of our knowledge this is the first publication depicting a framework for integrated technology and systems optimisation to design the best interventions across a property estate in a time-phased manner; guaranteeing a cost-effective transition to net zero carbon operations that are aligned with Science Based Targets.

The value and contribution of this research is very timely at a moment when carbon intensive organizations that are "big brands" for customers such as Amazon [43], Microsoft [44], and Sainsbury's [45] are making pledges to become net zero in operations by 2030 or 2040. Meanwhile, other retailers like Walmart are aligning their environmental targets to the Science Based Target framework [46]. These organisations and many more will soon face substantial challenges in undertaking cost-effective investments that both align in delivering value to shareholders but keep them on-track to meet their sustainability targets. It is through a comprehensive understanding of how best to integrate new business models in existing and new built environments with integrated energy solutions that zero carbon buildings and net zero operations will be achieved [47]. By doing so organisations will be able to develop trust-worthy low-carbon roadmaps that can be periodically reviewed [12].

This paper is composed of five sections. The current section has provided the motivation, background, purpose, and scope of the problem. The second section describes the methodology and mathematical formulation of the optimisation problem. The third section provides the results from the regression modelling and highlights the investment strategies derived from the optimisation solution. The fourth section discusses the results by covering the trade-offs from the various scenarios considered and covers the limitations of the modelling framework. The last section of this work provides concluding remarks.

\section{Methodology}

A comprehensive explanation of the approach taken to derive the low carbon investment strategy is outlined in this section. By first stating the high-level framework designed, it gives detailed insight into the models used and their underlying equations from the technologies simulations and is continued by the formulation of the MILP optimisation problem resulting from regression coefficients. 


\subsection{High-level description}

Food retailers who operate across many stores generally have three distinct site types, namely convenience stores, supermarkets and distribution centres. Clearly, each building type will have different characteristics and attributes, and so will differ in optimal technology choices to make them more sustainable. Supermarket buildings are the focus for this study as they comprise the largest number of sites (and have the largest share of carbon footprint) in retail organisations. The model proposed needs to consider the right mix of technologies required to establish a comprehensive decarbonisation programme of the estate. Due to their maturity and track-record, distributed energy systems are assumed to be the most effective technologies to mitigate emissions related with electricity and heat consumption [36]. To simplify the modelling complexity and reduce computation time only biomethane combined heat and power (CHP) engines and photovoltaic (PV) panels are considered here to deliver zero carbon buildings, as both technologies have the potential for a mass-scale transition not only for their environmental credentials but also due to their off-grid support [48].

Based on the arguments stated previously, a high-level schematic of the modelling methodology used in this work is shown in Figure 1. Firstly, the model inputs are collected, consisting of techno-economic databases covering 60 supermarket buildings of a diverse size dispersed throughout the UK and a wide range of distributed energy systems (i.e. CHPs and PVs) in terms of capacity. The dataset includes halfhourly supermarket natural gas and electricity load profiles, as well as store characteristics such as age, location and sales surface area. This vast dataset is compiled into an SQL database for convenience and access efficiency. An in-house program written in Python was implemented to connect to the specific database, retrieve the information requested and process it accordingly.

Investment Strategy Back End Architecture

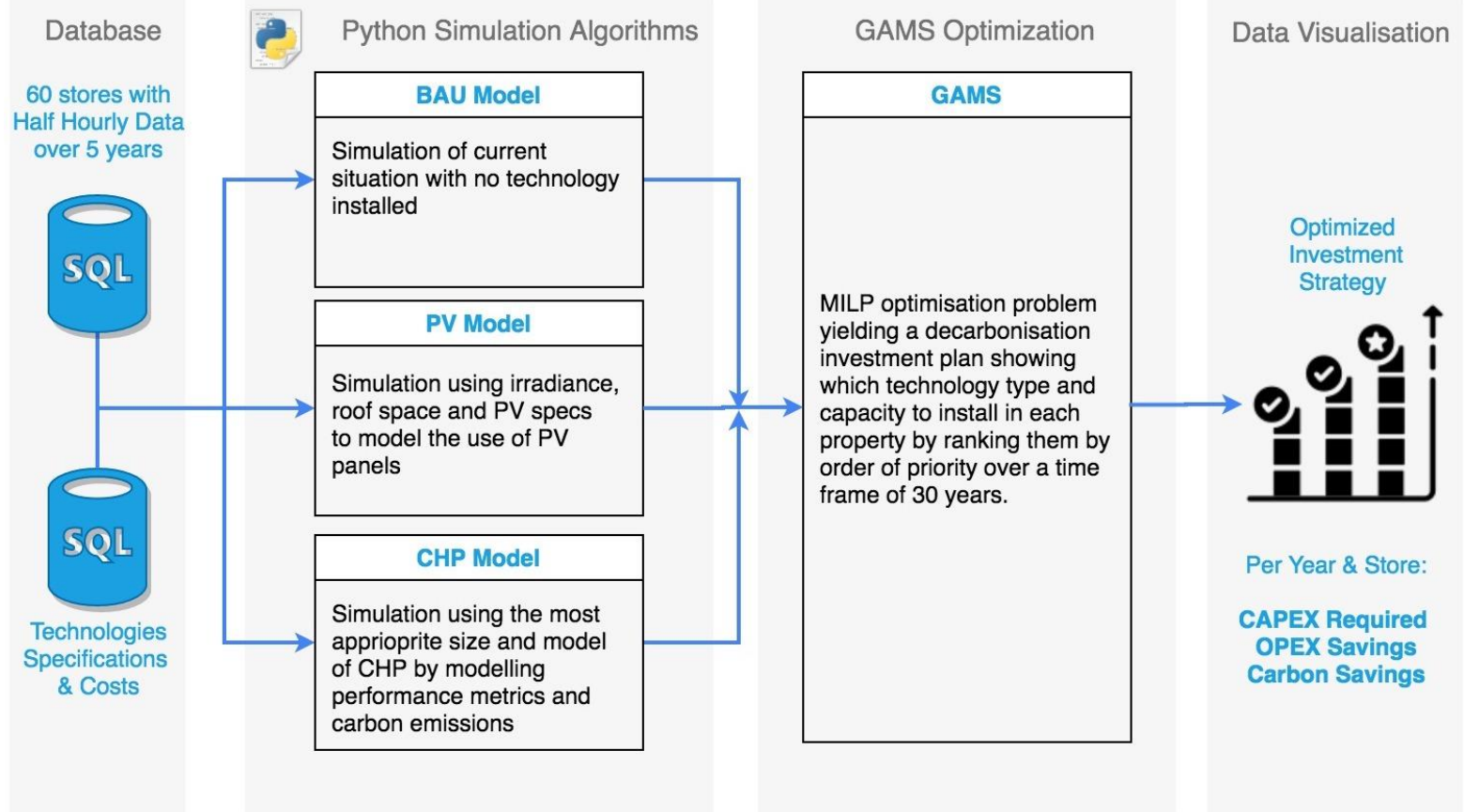

Figure 1: Methodology schematic detailing the data processing, modelling tools, and outputs derived from the model proposed.

Secondly, the simulation and optimisation blocks are devised into two parts employing Python and GAMS. Python simulation algorithms are employed to depict various building performance scenarios. These models allow us to quantify both "Business as Usual" (BaU) supermarket energy performance, without any low-carbon installations, and energy performance when low-carbon technologies are included. The PV and CHP models are based on the "TSO model" approach which has been described in previous publications addressing the characterisation and evaluation of CHPs and PVs in commercial 
buildings [33, 34]. We advise revising these works as they detail in-depth the data-driven energy systems optimisation approach that are summarised in this paper. The Python models were validated before being used to simulate the operation of each supermarket on a half-hourly basis, over a year. The simulation results show key performance indicators (KPIs) as a function of a possible technology mix for each supermarket. The KPIs are capital expenses (CAPEX), operational expenses (OPEX) and carbon emissions savings. The independent variables in the model are the size of the technologies, namely CHP system capacity and the PV capacity determined by the number of panels. The solution for each site is plotted showing the outcomes from installing different combinations of technologies. The relationship between the KPIs and the technology mix solution was then simplified using a linear regression model to generate a set of regression coefficients. To obtain linear coefficients, which fit this non-linear data, a multivariate adaptive regression splines (MARS) analysis is required. The MARS analysis splits the data into four domains; resulting in four sets of linear coefficients for each store simulated. The linear coefficients describing the performance of each supermarket, under different technology mixes, are then used as inputs into a master optimisation problem solved in GAMS. Solving the mixed integer linear programming (MILP) problem gives an optimised yearly investment plan (under a set of constraints), showing which technology type and capacity to install at each property, but most importantly it specifies the time and order of priority the investment has with respect to the whole estate.

Model outputs indicate the annual level of investment required and the resulting OPEX and carbon savings derived. As the investments cover a wide range, the temporal and spatial outputs can be represented utilising rich visualisation tools. Furthermore, since the modelling framework is adaptable, the optimisation problem can be solved for multiple scenarios underpinned by a divergent assessment of what the future might look like and which could directly impact decision-making in low carbon roadmap strategy. As the modelling framework expands up to the year 2050, many key parameters are subject to periodical revision, such as energy prices, technology costs, and the UK grid carbon factor; naturally, changes in these parameters could significantly steer the optimisation results. In this work, the forecasts considered are in line with the Future Energy Scenarios proposed by National Grid as they are constantly revising the evolution of the UK energy system [49]. Lastly, the MILP problem can also be modified to allow variable yearly capital investment, investigating the benefit of a flexible investment budget.

\subsection{Technology installation at individual sites}

A preliminary study was made of the entire property portfolio exceeding 600 supermarkets to create a representative sample by taking 4 factors into account: a) surface area, b) location, c) average energy demand and, d) age of the building. Firstly, the surface area was broken down into three sub-categories: small (Area $<25,000 \mathrm{ft}^{2}$ ), medium $\left(25,000<\right.$ Area $<45,000 \mathrm{ft}^{2}$ ) and large (Area $>45,000 \mathrm{ft}^{2}$ ). These boundaries allow to split the data in set sizes which are in the same order of magnitude as the original sample. The other three factors were taken to have an even spread across the range of values available to model different types of geographical locations which impact solar irradiance, and the age of buildings which impacts the energy demand of stores. This enabled to create a representative sample of 60 stores, about $10 \%$ of the original case study, to minimise the computing power necessary for the model to run.

\subsubsection{Calculating operating cost savings}

From the half-hourly energy demand data, the BaU scenario is simulated, representing operation with no technology installed. These costs are calculated by multiplying the load profiles with the half-hourly energy prices for natural gas and electricity; this serves to establish a cost baseline.

The operating cost savings for a single building from installing technologies are calculated by taking the difference between the discounted $\mathrm{BaU}$ operating costs and the discounted operating costs with technologies installed, over a 5-year period. This calculation includes the fixed periodic payment $(P p)$ for the installed technology, paid over its lifetime, assumed to be 30 years. 
The optimisation model output returns the ideal technology and capacity, financial indicators (i.e. payback time, CAPEX and cumulative discounted cash flow), and carbon emission savings. The key equations for determining costs are shown below:

$$
\text { Discounted } B A U O C=\sum_{t=0}^{M} \frac{B A U O c_{t}}{(1+r)^{t}}
$$

where, $t$ is the time period in years and $M$ is the number of time periods

$$
\begin{gathered}
\text { Discounted tech costs }=\sum_{t=0}^{M} \frac{(\text { tech } O c+P p)_{t}}{(1+r)^{t}} \\
\text { where } P p=\frac{r \times T i}{1-(1+r)^{-t f}}
\end{gathered}
$$

Operating cost savings $=$ Discounted $B A U O c-$ Discounted tech costs

\subsubsection{Simulation of technology size combinations}

The second section of the modelling approach involves simulating for each supermarket the installation of a specified number of PV panels and a specific size of CHP engine. This generates results for all possible technology combinations, which are used as inputs into the MILP GAMS optimisation.

To estimate the optimal technology size (i.e. capacity) for CHP engines and PV panels, simulations were run on a subset of 60 supermarkets. The subset was defined by ensuring a wide range of stores regarding energy demand, sales area, age, and location. Half-hourly demand data for a year was run through the Python code, which is comprised of a CHP engine model and a PV system model. The code runs simulations for all CHP systems (listed in Appendix A.1), and for all types of PV panels (see Appendix A.2). These calculations are divided into two sections to find the optimal technology size or number of panels for a store, as shown in Figure 1. For each supermarket, the optimal technology capacities and types are determined indicating the investment required.

The photovoltaic model simulates how adding panels on supermarkets' roofs impact OPEX and carbon savings. The power output of PV panels is calculated using the following equation:

$$
P=\operatorname{Ir} \times \text { eff } \times N_{p} \times A_{p} / 3,600
$$

Hourly irradiance data was retrieved from weather stations close to the supermarkets, sourced directly from the MIDAS database [50]. It was assumed that irradiance profiles are identical year on year. The PV panel efficiency is technology dependent and indicates the proportion of solar irradiance converted into electricity (see Appendix A.2 for more details). The number of panels $\left(N_{p}\right)$ installed is limited by the available roof space at each store, assumed equal to $60 \%$ of the sales area after consultation with Arthur Mariaud PV expert at Aggreko (personal communication, 31 October 24, 2019). This constraint ensures enough space for installation and maintenance access. Additional constraints, including roof maximum weight capacity, were considered to ensure project feasibility.

To calculate the CAPEX for PV panels, the model accounts engineering and installation expenses in addition to the unit price of PV panels. This includes the cost of installing supporting equipment such as the inverter, wiring, switches, a mounting system, a battery bank and a battery charger. These details are like previous projects presented in the literature [34] and is detailed in the following equation:

$$
P V \operatorname{CAPEX}(£)=N_{p} \times N P \times(P r+B O S)
$$


To ensure a rigorous PV analysis, the 2018 UK feed-in tariffs (FIT) were considered in the OPEX savings calculations; a popular policy supporting PV system uptake [51]. The FIT value depends on the total installed capacity at each site. However, because the FIT has been decreasing over the past decade, a low rate has been assumed to remain conservative in the analysis and avoid overestimation of the financial benefit derived from subsidies.

For installation of the CHP system, the cost includes both the technology CAPEX and engineering works required. These engineering works refer to mechanical or electrical modifications the facility requires and are assumed here at $£ 200,000$ per site. As suggested by Cedillos et al. [33] these costs vary as a function of engine capacity and building size. Moreover, the Enhanced Capital Allowance (ECA) is also considered, a UK tax policy for asset purchases [52], which results in a $26 \%$ reduction in the CAPEX of the technology and increases the attractiveness of CHP system installations. The CHP system capital costs are expressed in the following equation:

$$
\begin{gathered}
\text { CHP CAPEX }(£)=\text { CHP Price } \text { unit }_{1} \times E C A+\text { hidden costs } \\
\text { where hidden costs }=£ 200 k+A_{\text {store }} \times 2
\end{gathered}
$$

The CHP analysis calculates the OPEX and carbon reduction incurred when a CHP engine is installed. The model finds the optimal part-load operation of the engine based on the electricity and heat demands of the supermarket, while considering PV generation (if present). If the CHP engine is unable to meet the entire demand, grid electricity is imported. If the CHP electricity output is too high, the excess is exported to the grid and sold. These dynamics are modelled through the following equations:

$$
\begin{gathered}
E p=a_{f u e l} \times P L+b_{\text {fuel }} \\
H p=a_{t h} \times P L+b_{t h} \\
\text { OPEX = (CHP gas consumption } \left.+\frac{T d-H p}{\text { Boiler }_{\text {eff }}}\right) \times \text { Price }_{\text {gas }}+(E d-E p) \times \text { Price }_{\text {elec }}
\end{gathered}
$$

The CHP model assumes the only fuel used is biomethane, which has a carbon factor of 0.00538 $\mathrm{kgCO}_{2} \mathrm{e} / \mathrm{kWh}$, two orders of magnitude lower than the $0.184 \mathrm{~kg} \mathrm{CO}_{2} \mathrm{e} / \mathrm{kWh}$ of natural gas, used in the $\mathrm{BaU}$ model to supply heating via conventional boilers. The BaU grid electricity carbon factor for year 1 of the simulation was set at $0.351 \mathrm{kgCO}_{2} \mathrm{e} / \mathrm{kWh}$ as indicated by the 2018 BEIS Department of the UK Government [53]. Henceforth, in this work biomethane availability is not a concern although research indicates scaling-up of this valuable resource still requires much work [54].

\subsection{Regression method}

The methodology described in Section 2.2 was applied to a subset of 60 supermarkets to obtain CAPEX requirements, OPEX savings and carbon savings for each technology combination. These results then serve as inputs into a MILP, developed in GAMS, to find the optimal sequence of investments across the property portfolio. To reduce computational time this information was simplified using linear regression. However, it was observed that the data set for both carbon savings and OPEX savings were not correlated linearly to CHP engine capacity. Therefore, to generate linear regression coefficients on non-linear data points, a MARS analysis was used to minimise the prediction error. The MARS analysis splits the data into four domains and generates a regression model for each one of those datasets. It calculates the prediction error and reiterates using different bounds for the domains, generated randomly. After a set of iterations, the model outputs the regression coefficients and bounds which minimise the residual sum of the squares, giving the best possible fit.

The dependent variables for this case study are the number of PV panels and the CHP engine size, which are plotted against CAPEX, OPEX savings or carbon savings. In each domain, the coefficients calculated fit the data according to the following linear regression equation:

$$
Y=a x_{1}+b x_{2}+c
$$


The independent variables are $x_{1}$ and $x_{2}, Y$ is a dependent variable and fitting parameters $a, b$ and $c$ are adjusted to fit the data. In the domain containing the point $(0,0)$, meaning that no PV panels nor CHP engines have been installed, the coefficient $c$ is forced to be zero to avoid calculating savings even when no technologies are installed.

To find the fitting parameters, the non-linear least square method was used. Subsequently, to evaluate how well the regression model fits the data, the variance score, average absolute error, relative error and residual sum of squares were determined, as stated in equations 12 to 15 . The variance score is a Python regression score function that computes the $R^{2}$, also known as the coefficient of determination, with a best possible score of 1 .

$$
\begin{gathered}
R^{2}(y, \hat{y})=1-\frac{\sum_{i=0}^{n_{\text {samples }}-1}\left(y_{i}-\hat{y}_{i}\right)^{2}}{\sum_{i=0}^{n_{\text {samples }}-1}\left(y_{i}-\bar{y}\right)^{2}} \quad(12) \quad \text { where } \quad \bar{y}=\frac{1}{n_{\text {samples }}} \sum_{i=0}^{n_{\text {samples }}-1} y_{i} \\
\text { Absolute error }=\text { abs }(\text { Predicted value }- \text { data value }) \\
\text { Relative error }(\%)=\frac{\text { abs }(\text { Predicted value }- \text { data value })}{\text { predicted value }} \times 100 \\
\text { Residual sum of squares }=\sum(\text { Predicted value }- \text { data value })^{2}
\end{gathered}
$$

\subsection{MILP optimisation}

To run the MILP optimisation, the MARS analysis regression coefficients and linear regressions for all stores up to 2050 are incorporated into the model. The optimisation allows the model to calculate the carbon and OPEX reductions and therefore the sequence of investments to derive a cost-effective lowcarbon roadmap.

\subsubsection{Objective function and operating costs and carbon emissions}

The objective function minimises total costs derived from the technology investments and the sum of the resulting operating costs after their installation in 60 buildings considering a time frame of 30 years. The results provide insight on the optimal size, $s$, and technology, tech, to install in each store, and on what year, $t$, to undertake such investment. The objective function formulation is given in the following equation:

$$
\min f=\sum_{t} Y i(t)-\sum_{t} \sum_{s} O P E X S a(t, s)
$$

As mentioned above, the annual OPEX and $\mathrm{CO}_{2} \mathrm{e}$ savings are calculated through the regression coefficients inputted into the model. These coefficients correspond to a certain store, $s$, for a certain time, $t$, technology, tech, and domain of regression, $d$. Equations 18 to 22 enable the calculation of these values. The binary variable $C o_{i}$ ensures that the correct coefficients, $K_{i}$, are associated with the correct technology size, $x$, ranging between the lower and upper bound of the domain of regression. The sum of $C o_{i}$ over the domain set, $d$, stated in equations 17 to 21, ensures that the savings are not counted twice. The parameter $M$, equal to $10^{6}$, is a large number to allow for a MILP formulation. 


$$
\begin{gathered}
g_{1}: \operatorname{Sa}_{i}(t, s)>\sum_{t e c h} K_{i}(d, \text { tech }, t, s) \times x(\text { tech }, t, s)-\left(1-\operatorname{Co}_{i}(d, t, s)\right) \times \mathrm{M} \\
g_{2}: S a_{i}(t, s)<\sum_{\text {tech }} K_{i}(d, \text { tech }, t, s) \times x(\text { tech }, t, s)+\left(1-\operatorname{Co}_{i}(d, t, s)\right) \times \mathrm{M} \\
\left.g_{3}: x(\text { tech }, t, s)>L b_{i}(d, \text { tech }, t, s)-\operatorname{Co}_{i}(d, t, s)\right) \times \mathrm{M} \\
\left.g_{4}: x(\text { tech }, t, s)<L t_{i}(d, \text { tech }, t, s) \operatorname{Co}_{i}(d, t, s)\right) \times \mathrm{M} \\
h_{1}: \sum_{d}\left(\operatorname{Co}_{i}(d, t, s)\right)=1 \\
\text { where } i=\{O P E X, C O 2\}
\end{gathered}
$$

\subsubsection{Capital investment}

Having calculated the savings, the CAPEX required to install the technologies has to be calculated. The calculation is the sum of all investments made, on all sites, and comprises two parts, described in equation 22. The first is valid for modular technologies like PV solar panels, where the regression coefficient is timed by the difference between the total amount installed in year $t$, and the amount previously installed in year $t-1$. This ensures all panels are not reinstalled for every increase in size. However, as CHP engines are non-modular, the capex is calculated simply as $\mathrm{Nm}$.

$$
\begin{aligned}
h_{2}: \operatorname{capex}(t, s) & =\sum_{t e c h} K 1_{\text {CAPEX }}(\text { tech }, t) \times(x(\text { tech }, t, s)-x(\text { tech }, t-1, s)) \\
& +N m(\text { tech }, t, s)
\end{aligned}
$$

The CAPEX for CHP engines is calculated using the regression coefficients inputted into the model, and a binary variable $I O$.

$$
\begin{gathered}
g_{5}: N m(\text { tech }, t, s)>K 0_{\text {CAPEX }}(\text { tech }, t)+K 1_{\text {CAPEX }}(\text { tech }, t) \times x(\text { tech }, t, s)- \\
(1-I O(\text { tech }, t, s) \times 100000) \\
g_{6}: I O(\text { tech }, t, s)>x(\text { tech }, t, s)-x(\text { tech }, t-1, s) \times 0.0001-M o(\text { tech }) * 100000
\end{gathered}
$$

If a technology is modular, $M o=1$, or a larger technology is not installed between $t-1$ and $t, I O$ is driven to 0 , as shown in equation 24 , and this results in a null $\mathrm{Nm}$ in equation 23 . In the opposite scenario when a technology is modular, and a larger technology is installed, equation 25 applies:

$$
\begin{aligned}
& I O=1 \\
& N m(\text { tech }, t, s)=K 0_{C A P E X}(\text { tech }, t)+K 1_{\text {CAPEX }}(\text { tech }, t) \times x(\text { tech }, t, s)
\end{aligned}
$$

\subsubsection{Problem constraints}

The following constraints have been applied to the model. Equation 26 caps the total annual CAPEX to the same value for each year, to avoid making all the investments at the beginning of the 30-year horizon. Spreading the investments over the time horizon is likely favourable for businesses. Equation 27 ensures the capacity size of the technology can only be increased as time progresses, preventing removal of previously installed technologies. Finally, equation 28 sets a minimum annual carbon reduction target. 


$$
\begin{gathered}
g_{7}: \sum_{s} \operatorname{capex}(t, s)<Y i(t) \\
g_{8}: x(\text { tech }, t, s)>x(\text { tech }, t-1, s) \\
g_{9}: \sum_{S} S a_{C O 2}(t, s)>S t(t)
\end{gathered}
$$

\subsubsection{Payback time and time value of money constraints}

Equation 29 was used to calculate the simple payback period of investments at a given point in time, dividing the capital investment of installing new technology by its marginal OPEX savings:

$$
\operatorname{Payback}(t)=\frac{\operatorname{Capex}_{(t)}}{\operatorname{Opex}_{(t)}-\operatorname{Opex}_{(t-1)}}
$$

To improve the model further, it was decided to introduce additional complexity to provide more insights by considering the time value of money. Two additional constraints are therefore included, which add flexibility to the investments made. They enable annual investments to vary from year to year by a factor of $(1-\alpha)$ to $(1+\alpha)$, where $0<\alpha<1$. For the simulations made throughout this work $\alpha$ was set to 0.3 , or a variation of $30 \%$.

\section{Results}

Having calculated the KPIs for each store, and a range of technology types and sizes, it is necessary to approximate this data using linear regression so it can be input to the MILP optimisation problem. First, the results of the regression model as well as the relative error associated with it are presented in this section. It is followed by a description of the different scenarios used in the model to forecast different key parameters for the 2020-2050 time frame in which the case study is conducted. The resulting investment strategy is then explained for each scenario by presenting CAPEX, OPEX and carbon savings. Finally, a variation of the "Steady State" scenario with the time value of money considered is covered more in depth with a list a of the first stores being invested into.

\subsection{Capital costs}

The CAPEX coefficients only depend on the time horizon analysed, as it was assumed the price of each technology would decrease over time due to technological innovation and reduction in installation costs. The calculation is done individually for each technology, before a simple linear regression is fitted to each set of data, according to equations 30 and 31 where the variable $x_{l}$ is the technology size.

$$
\begin{gathered}
C H P C A P E X(£)=587 x_{1}+108,000 \\
P V \operatorname{CAPEX}(£)=128 x_{1}
\end{gathered}
$$




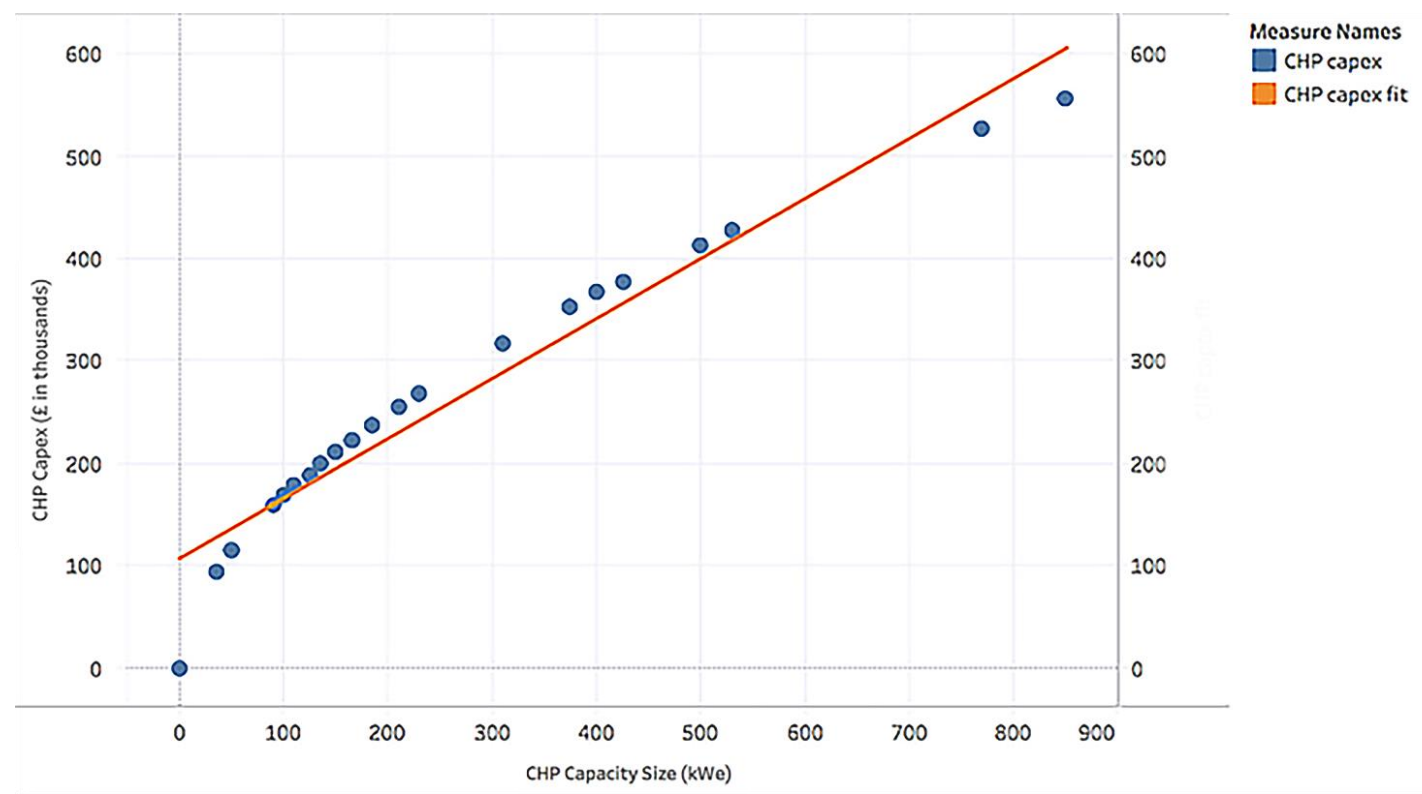

Figure 2. Linear regression of CHP CAPEX investment against capacity size $\left(k W_{e}\right)$.

Figure 2 shows the CHP CAPEX investment against capacity size in year 2020, along with the linear regression fit. The plot indicates the CHP CAPEX increases at a decreasing rate, with the slope reducing as a function of size. The plot is approximated using linear regression, in order to compute an optimised solution in a MILP, giving an $\mathrm{R}^{2}$ mean square error of 0.945 and a mean relative error of $11.8 \%$. That the regression does not pass through the origin is accounted for by a binary variable forcing the CAPEX to zero if no CHP is installed in the GAMS model.

As it can be seen from the PV model method (Section 2.2.2, Eq. 6), the PV CAPEX is calculated by multiplying the number of panels by a fixed price. Therefore, the fit is perfect with $R^{2}=1$. In practice, as the number of panels purchased increases, the price per panel might be subject to economies of scale and consequently decrease. However, a conservative approach was used in this work and maintains the unit price at a constant value, as depicted in Figure 3.

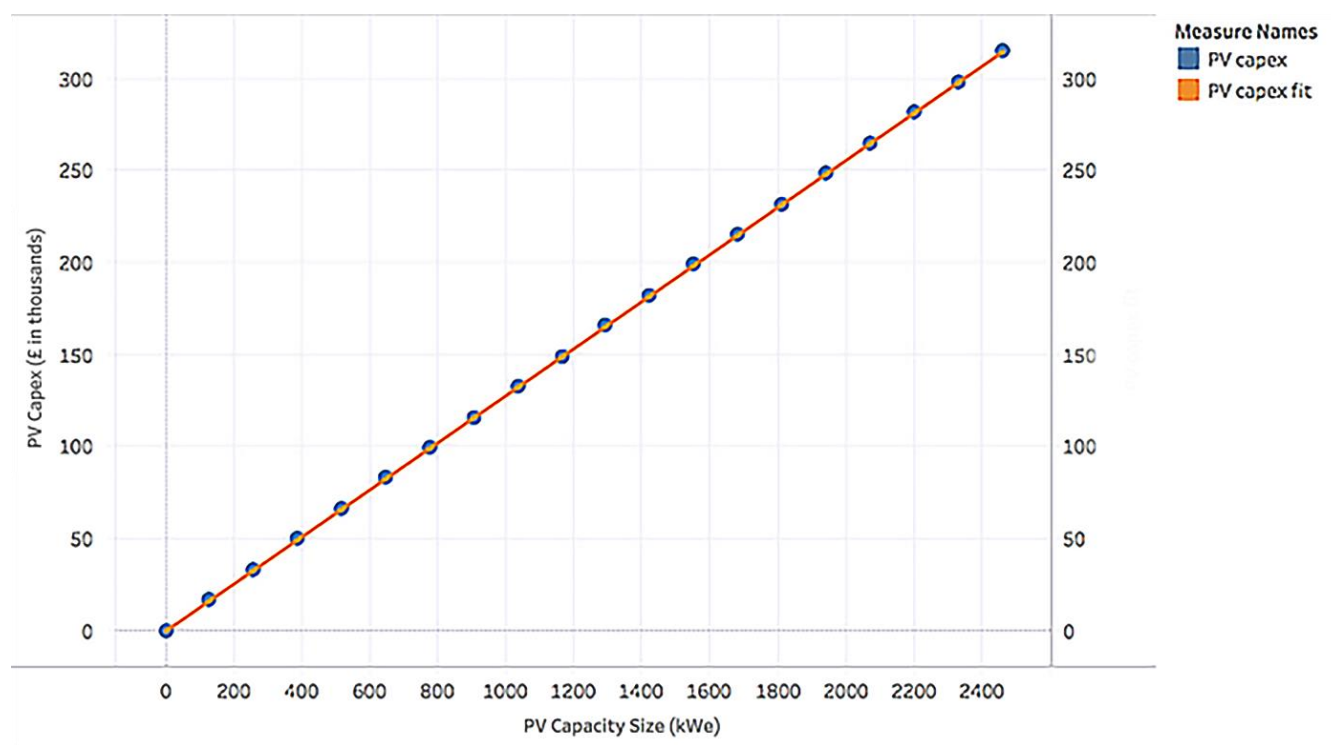

Figure 3. Linear regression of PV CAPEX against capacity size (e.g. number of panels).

\subsection{Carbon and operational cost savings}

The data calculated for annual carbon and OPEX savings is not linearly correlated to CHP capacity size. The savings do initially increase almost linearly, though at a certain point then plateau, sometimes 
even slightly decreasing. This observed inflection point occurs when the CHP engine size is large enough to cover most of a store's demand, and the electricity imports from the grid near zero. In this work it was assumed CHP engines can only operate at a minimum part-load of $60 \%$, as the engine maintenance costs, and lifespan would otherwise be negatively influenced [33]. Meanwhile, installing a larger engine would be techno-economically inefficient, increasing the biomethane consumption, and thus the operating costs and emissions. To minimise the prediction error when using linear regression for non-linear data, MARS analysis was used.

The fit and error were calculated for the regression models of all 60 stores to evaluate the accuracy of the predictions. It was found that the OPEX savings are predicted well, with an average $\mathrm{R}^{2}$ of 0.95 and mean relative error of $2.4 \%$, whereas the carbon savings prediction is not as accurate, with a mean $\mathrm{R}^{2}$ of 0.71 and a mean relative error of $7.6 \%$. This is primarily due to the regression models being forced through the origin to set carbon and OPEX savings to zero when no technology is installed. This particularly impacts the carbon savings, as there is an initial step increase up from zero, resulting from installation of a CHP engine. However, OPEX savings reduce linearly as technologies are installed, limiting the error produced by forcing the fit through the origin.

Table 2: MARS fit and mean relative errors for operational and carbon savings.

\begin{tabular}{|c|c|c|c|}
\hline Parameter & Indicator & OPEX & Carbon Emissions \\
\hline \multirow{2}{*}{$\mathrm{R}^{2}$ score } & Mean & 0.95 & 0.71 \\
\cline { 2 - 4 } & Standard deviation & 0.11 & 0.32 \\
\hline \multirow{2}{*}{ Relative error } & Mean & $2.4 \%$ & $7.6 \%$ \\
\cline { 2 - 4 } & Standard deviation & $1.7 \%$ & $6.7 \%$ \\
\hline
\end{tabular}

\subsection{Roadmap scenarios}

The investment strategy roadmaps employ the regression results discussed in Sections 3.1 and 3.2. Because investments need to be done in a sequenced manner and could shift based on changing market conditions, the optimisations results offer a clear roadmap to mitigate carbon emissions based on informed future scenarios the decision-makers might encounter. The scenarios described in this section, based on National Grid reports, serve as guidelines to quantify how investment strategies could vary according to the evolution of the UK energy system. The ability to analyse different scenarios is a great strength of the model, comparing alternative investment strategies and offering a wide range of solutions that are influenced by market variations and policies.

\section{Scenarios overview}

When devising an investment strategy from 2020 up to 2050, it is important to consider that external factors are unlikely to remain constant. For instance, important technological and market changes evolve incrementally, such as the uptake of renewable energy systems which impact the UK's energy landscape. It is therefore required to make informed predictions in future trends of external parameters to devise plausible scenarios and understand how low-carbon roadmap investment strategies could deviate from each other.

Each year, National Grid (the UK electricity system operator), gathers impartial information from stakeholders across the energy industry and presents them in the Future Energy Scenarios publications to support decision making for organizations [49]. The set of four credible pathways proposed by National Grid are: "Steady State", "Two Degrees", "Slow Progression", and "Consumer Power". Each one of these scenarios considers the energy trilemma comprising security of supply, affordability and carbon intensity, which impacts both large and small consumers alike; these scenarios are:

- The Steady State scenario sees the slowest economic growth and is not environmentally ambitious. It is where BaU prevails, and the energy industry's focus is to ensure low-cost security of supply. This results in the lowest levels of long-term investment and a slow reduction in the carbon factor of electricity. There is no tax on the use of natural gas, few 
incentives to encourage transition to green sources of energy, and electricity prices do not increase substantially due to limited subsidies supporting renewable generation resources.

- The Two Degrees scenario has the highest level of prosperity and desire to decarbonise the economy. This results in a high level of investment in renewable energy, new green technologies, and low carbon fuel gas innovation, the latter increasing the biomethane capacity. Additionally, there is a global green consciousness which leads to incentives and policies being put in place, and high taxes are levied on carbon emitters; thus, increasing energy prices and decarbonising the grid at a faster pace. All these factors together lead to significant decarbonisation, making this the only scenario in which the legal UK carbon reduction targets are met [55].

- In the Slow Progression scenario, there is a collective desire to decarbonise the economy, however progress is limited by slow economic growth. Cost-efficient long-term incentives and policies are put in place, and an increase in distributed generation is observed, but the adoption rate is slow by lack of financial resources, therefore the decarbonisation rate is not as fast as in the "Two Degrees" scenario.

- The Consumer Power scenario has high economic growth, but limited ambition to become environmentally friendly. The consumers' behaviour is led by their appetite for novel technologies, which results in market-led investments. Spending is therefore focused on small-scale generation to produce attractive financial returns. There is minimal government incentives or policies for renewable energy generation, and decisions are made at local level; making it harder to decarbonise the grid.

Based on the above scenarios, quantitative trends of external parameters were devised and are detailed in Table 3. For simplicity, these projections are constant across the time period covered by the roadmap (i.e. 30 years). The key parameters considered are electricity, natural gas and biomethane market prices, as well as the capital cost of PV panels and CHP engines, and the electricity grid carbon factor.

Table 3: Values and annual percentage variation of key parameters under each scenario.

\begin{tabular}{|c|c|c|c|c|c|c|}
\hline & $\begin{array}{c}\text { Electricity } \\
\text { price } \\
(\mathrm{p} / \mathrm{kWh})\end{array}$ & $\begin{array}{c}\text { Natural gas } \\
\text { price } \\
(\mathrm{p} / \mathrm{kWh})\end{array}$ & $\begin{array}{c}\text { Biomethane } \\
\text { price (p/kWh) }\end{array}$ & $\begin{array}{c}\text { CHP unit } \\
\text { price range } \\
(\mathrm{kf} / \mathrm{unit})\end{array}$ & $\begin{array}{c}\text { PV system } \\
\text { price range } \\
\left(£ / \mathrm{kW}_{\mathrm{p}}\right)\end{array}$ & $\begin{array}{c}\text { Carbon factor } \\
\left(\mathrm{kgCO}_{2} \mathrm{e} / \mathrm{kWh}\right)\end{array}$ \\
\hline $\begin{array}{c}\text { Initial values } \\
\text { (i.e. 2020) }\end{array}$ & 11.9 & 2.35 & 2.89 & 95 to 556 & 437 & 0.351 \\
\hline Steady State & $+4.5 \%$ & $+2.5 \%$ & $+2.5 \%$ & $-0.25 \%$ & $-0.75 \%$ & $-3 \%$ \\
\hline Two Degrees & $+7 \%$ & $+3.5 \%$ & $+3.5 \%$ & $-0.25 \%$ & $-1.5 \%$ & $-6 \%$ \\
\hline $\begin{array}{c}\text { Slow } \\
\text { Progression }\end{array}$ & $+6 \%$ & $+3 \%$ & $+3 \%$ & $-0.25 \%$ & $-1 \%$ & $-4 \%$ \\
\hline $\begin{array}{c}\text { Consumer } \\
\text { power }\end{array}$ & $+3.5 \%$ & $+3.5 \%$ & $+3.5 \%$ & $-0.5 \%$ & $-1.25 \%$ & $-3 \%$ \\
\hline
\end{tabular}

\subsection{Investment strategy: Capital costs and technologies}

The annual CAPEX is forced by a constraint in the model to be constant year on year, based on the assumption that a constant investment level will be most favourable to food retail businesses as it provides budget certainty. The average annual investment across all scenarios is $£ 2.36$ million for the 60 supermarkets considered. As detailed in Table 4, the scenario requiring the least CAPEX is "Consumer Power", as decarbonisation is not the primary focus, whereas "Two Degrees" requires the most capital investment due to strong societal desire to decarbonise.

Table 4: Annual average CAPEX required for each Future Energy Scenario considered.

\begin{tabular}{|c|c|c|c|c|}
\hline Variable & Steady State & Two Degrees & Slow Progression & Consumer Power \\
\hline
\end{tabular}

\footnotetext{
${ }^{1}$ Cost subject to CHP system electricity capacity output in $\mathrm{kW}_{\mathrm{e}}$.
} 


\begin{tabular}{|c|c|c|c|c|}
\hline $\begin{array}{c}\text { Capital costs } \\
(£ \text { millions })\end{array}$ & $£ 2.30$ & $£ 2.70$ & $£ 2.45$ & $£ 1.90$ \\
\hline
\end{tabular}

The CAPEX is directly correlated to the technologies installed in each store. The overall capacity installed is plotted over time for CHP and PV systems in Figures 4 and 5; respectively. Interestingly, all four scenarios follow similar trends, showing the similarities and robustness of the investment strategies, even if external factors vary. As installed capacity increases, new assets are being added to specific stores. However, as the curve flattens out, most notably for CHP units, it implies the on-site technologies almost fully supply site demand. The model suggests that the optimal strategy requires adding CHP engines aggressively in the first 10 years whilst investing in PV panels ramps up by 2030. It is important to note that while the scenarios ultimately have comparable total capacity installed by 2050 , (16 to $18 \mathrm{MW}_{\mathrm{e}}$ for CHPs and 23 to $24 \mathrm{MW}_{\mathrm{p}}$ for PVs), the rate of investment and the specific stores addressed varies across scenarios as exemplified in Section 3.7. Overall, results indicate that the "Consumer Power" scenario ends up being the scenario with the most installed capacity, which is reasonable as in this context the end-users are willing to increase smallscale generation to produce attractive financial returns.

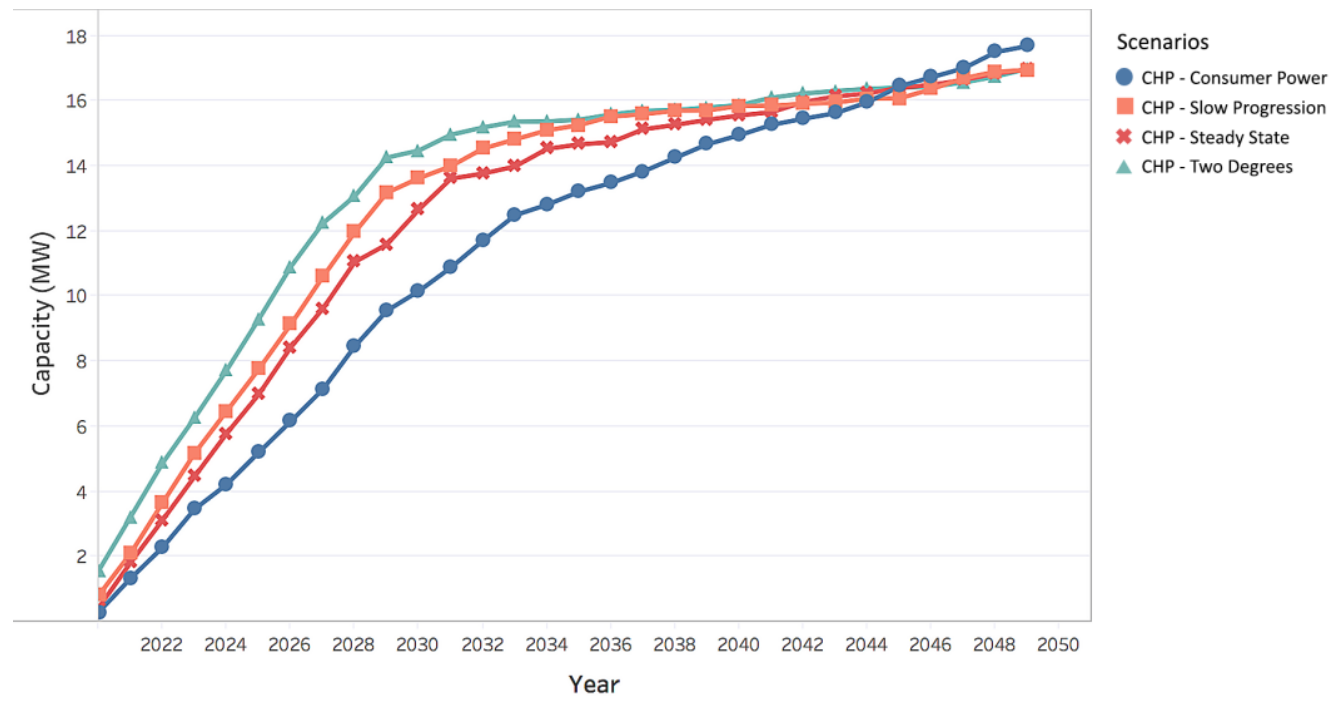

Figure 4. CHP engine capacity installed for different scenarios up to 2050.

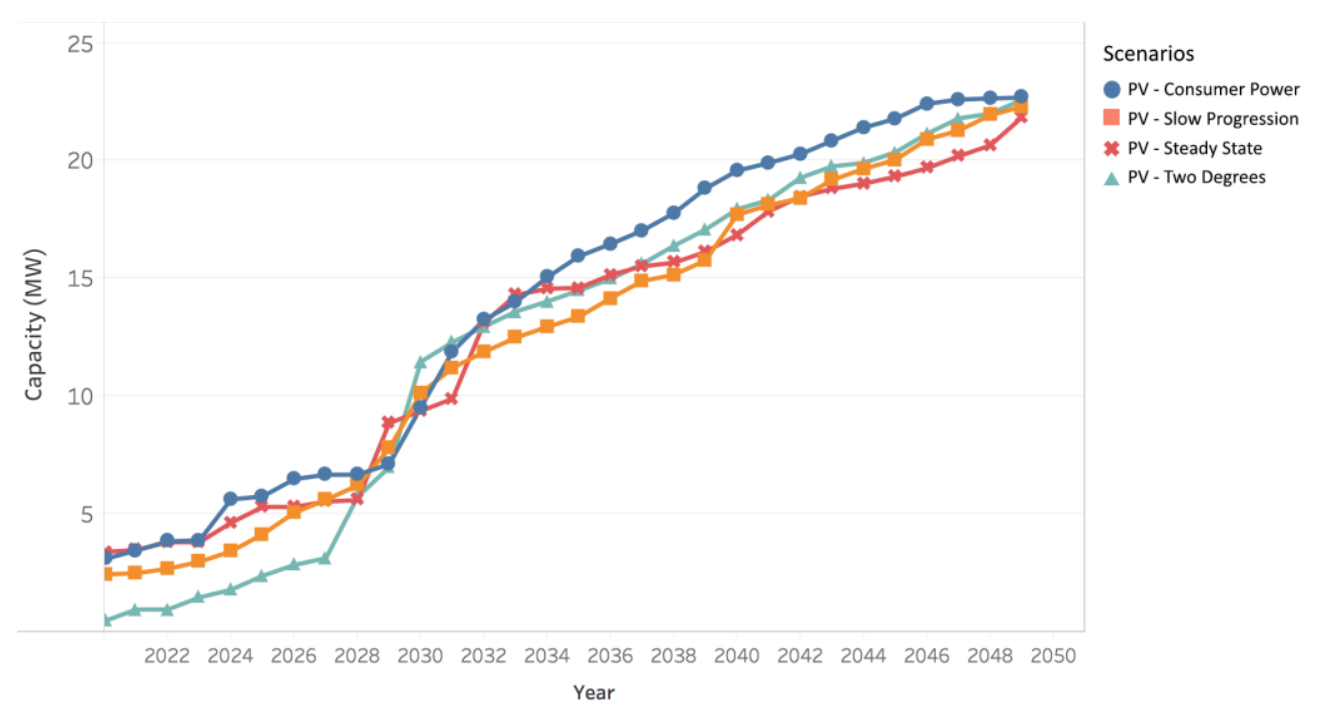

Figure 5. PV system capacity installed for different scenarios up to 2050.

\subsection{Investment strategy: OPEX savings}

Annual operational savings are calculated and contrasted against the $\mathrm{BaU}$ model (where no investment takes place). The sum of OPEX savings over time, for the 60 stores, is plotted in Figure 6 . As expected, 
savings increase annually, but the "Two Degrees" scenario generates the highest savings reaching almost $£ 70$ million by 2050 . This is primarily because this scenario has the highest electricity prices, meaning adding on-site technologies leads to greater savings. The other scenarios are more conservative; however they all predict savings greater than $£ 10$ million by 2040 .

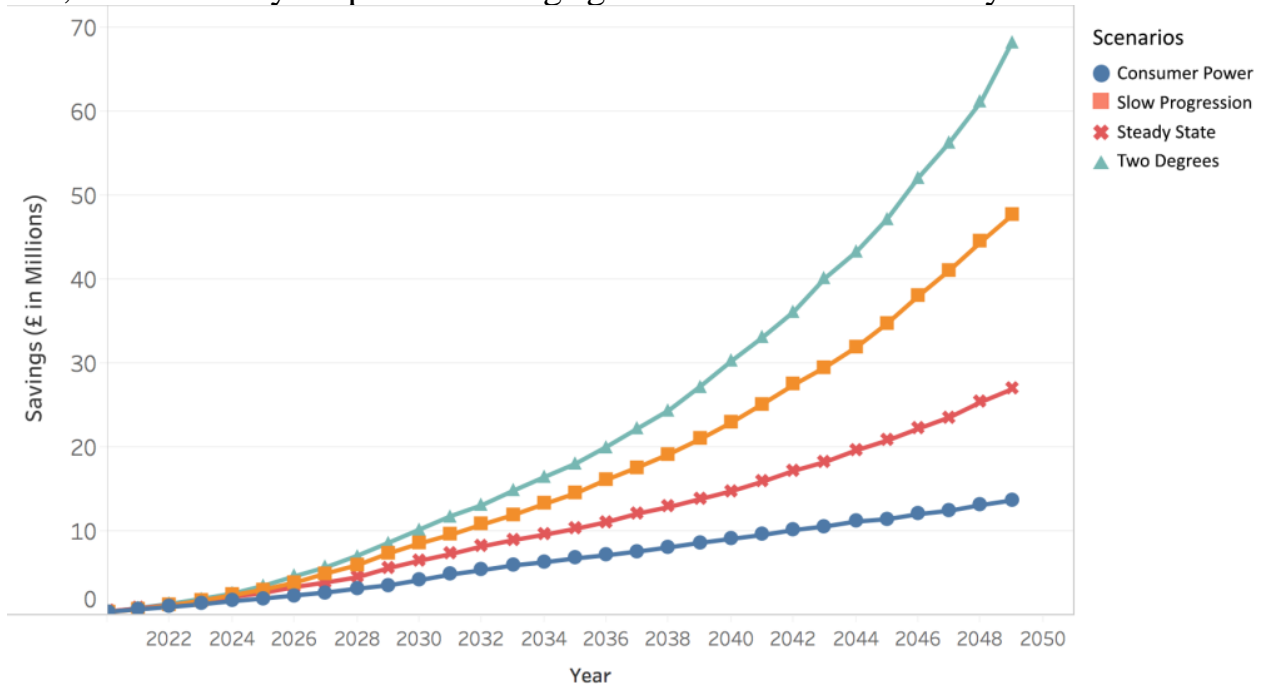

Figure 6. Annual OPEX savings for different scenarios up to 2050.

\subsection{Investment strategy: Carbon savings}

The model allows plotting the decarbonisation pathways for each roadmap scenario and compares their evolution against science-based targets. Two emissions targets are set to evaluate trajectory success, namely $55 \%$ reduction by 2030 , and $98 \%$ by 2050 . Emissions reduction trajectories for each scenario are plotted in Figure 7. For every scenario, the 2030 target is met ahead of schedule, although "Consumer Power" is slower in reducing carbon emissions, meeting its target in 2029. Meanwhile, 2050 targets are reached under the "Two Degrees" and "Slow Progression" scenarios by 2041, with the "Steady State" scenario falling just short. The "Consumer Power" scenario however falls way short of the 2050 target by more than $10 \mathrm{ktCO}_{2} \mathrm{e}$.

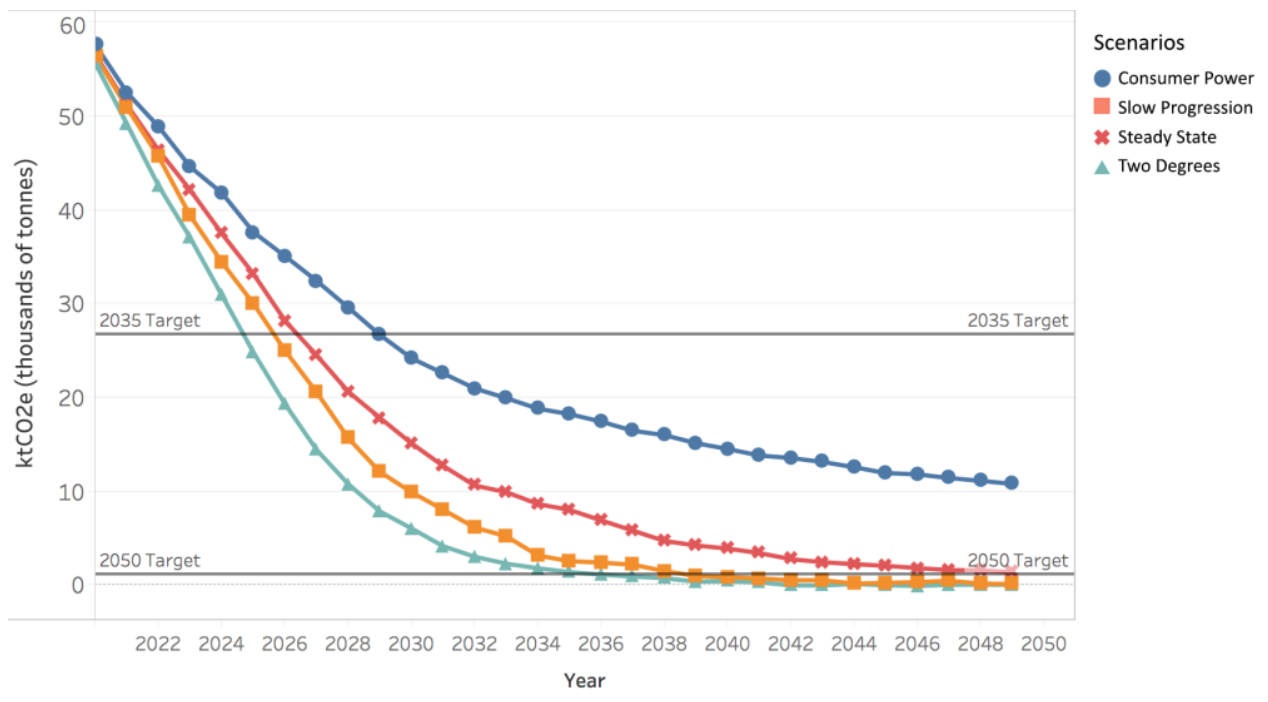

Figure 7. Carbon footprint trajectories for different scenarios up to 2050.

\subsection{In-depth analysis: The "Steady State" scenario}

To provide a deeper understanding of the simulation's potential in advising strategic investment decisions, the "Steady State" scenario is further analysed to highlight the utility and flexibility of the model; this scenario was chosen as it models current UK energy policy. 


\subsubsection{Capital costs and technologies}

In this section the assumption that the decision-maker has a constant amount to invest each year is disregarded, with flexible annual investments feasible, thus giving decision-makers the capability of changing the level of investment. Having removed the assumption of constant annual CAPEX, results indicate that annual CAPEX could vary year-on-year by up to $30 \%$. Furthermore, when the time value of money is considered (as explained in Section 2.4.5), results suggests the frontloading of investment. Investment in year 1 (2020) is $£ 7$ million, falling steadily to approximately $£ 1$ million annually from 2030 onwards. The CAPEX investments are segmented into small, medium and large supermarket buildings (based on sales area size), with larger stores requiring greater CAPEX due to larger energy demands. Consequently, large and medium stores make up most of the expenditure. Small stores are smaller than $25,000 \mathrm{ft}^{2}$, medium is for stores between $25,000-45,000 \mathrm{ft}^{2}$, and large stores have a surface area greater than $45,000 \mathrm{ft}^{2}$. Figure 8 shows the level of investment each type of store receives per year.

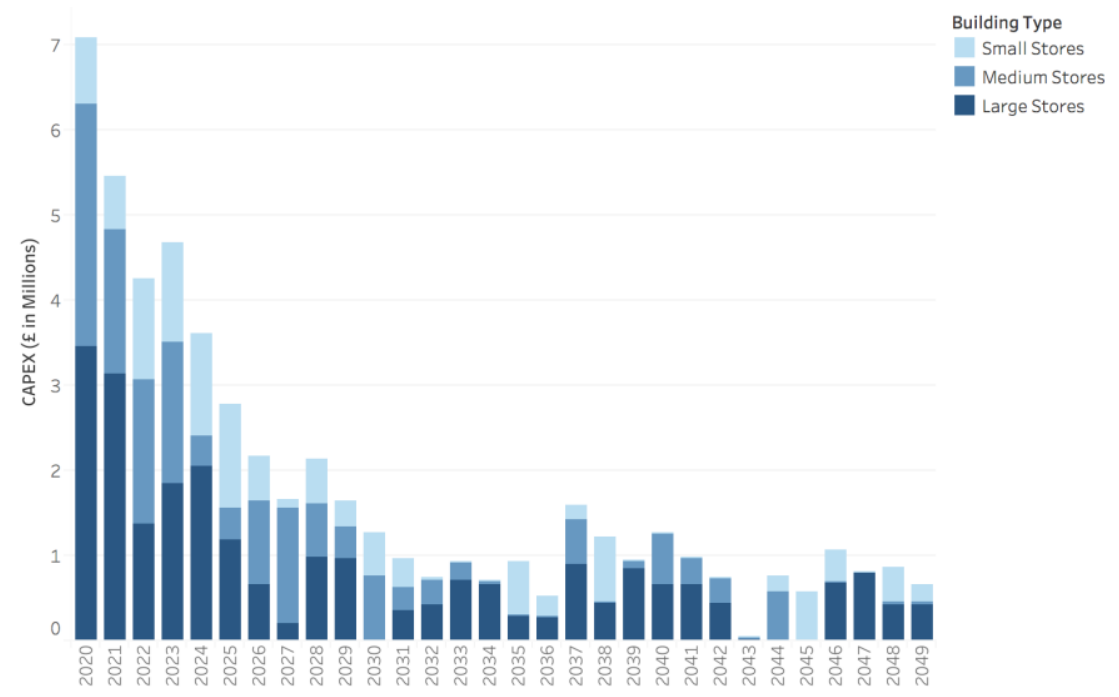

Figure 8. Annual CAPEX results when investment flexibility is allowed in the "Steady State" scenario.

Figure 9 describes the aggregated power capacity installed for both CHP engines and PV systems over the years for each store type. CHP engines are installed mostly in large stores, followed by medium sores and minimal investment in smaller sites, with the same trend applying to PV systems. CHP installed capacity plateaus close to $10 \mathrm{MW}_{\mathrm{e}}$, while PV system capacity caps at about $22 \mathrm{MW}_{\mathrm{p}}$.

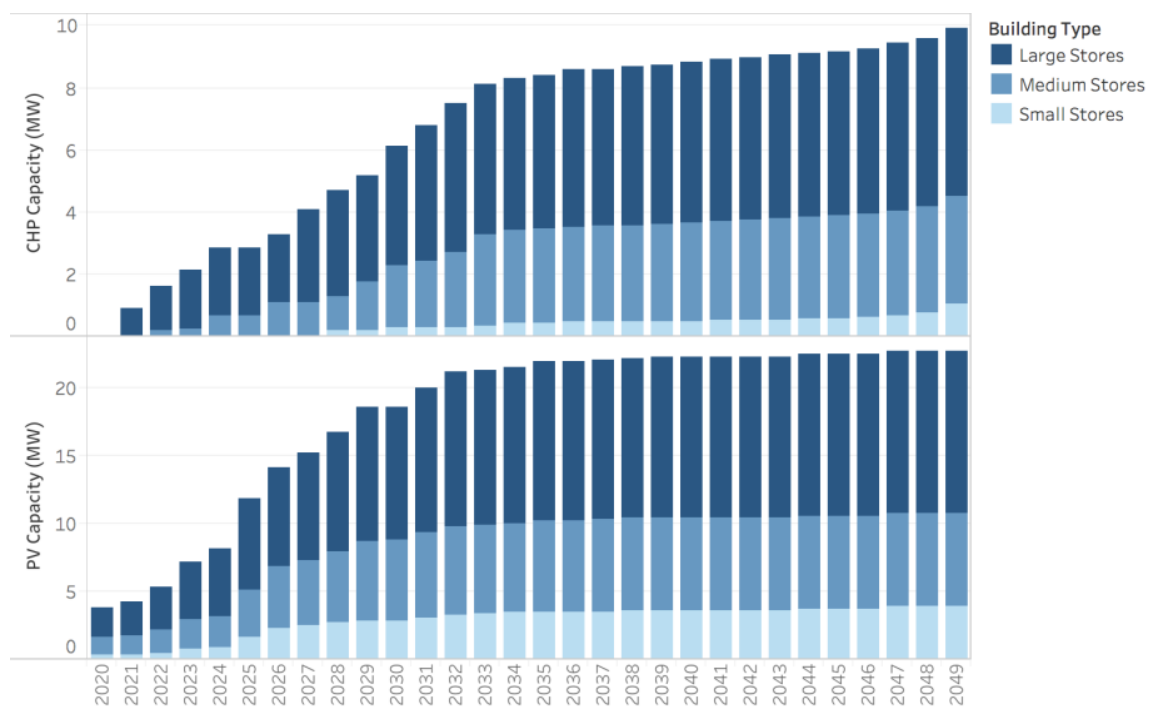

Figure 9. Aggregated installed capacity over time for each technology in the "Steady State" scenario. 


\subsubsection{Sequence of investments}

Another powerful insight the model provides is the investment programme sequence by order of priority. Taking the "Steady State" scenario result with a constant annual CAPEX budget of $£ 2.3$ million (see Table 4), Table 5 summarizes the top 10 sites with the greatest carbon savings out of 34 investments in year one under the "Steady State" scenario (see Appendix B.1 for the full list). The model outputs key techno-economic KPIs, informing decision-makers on various investment KPIs, including capacity, payback time, and carbon savings.

Table 5: Preferred 10 stores for investment in the first year of the "Steady State" scenario.

\begin{tabular}{|c|c|c|c|c|c|c|c|}
\hline Store & $\begin{array}{c}\text { Building } \\
\text { Type }\end{array}$ & $\begin{array}{c}\text { CHP } \\
\text { Capacity } \\
\left(\mathrm{MW}_{\mathrm{e}}\right)\end{array}$ & $\begin{array}{c}\mathrm{PV} \\
\text { Capacity } \\
\left(\mathrm{MW}_{\mathrm{p}}\right)\end{array}$ & $\begin{array}{c}\text { CAPEX } \\
(\mathrm{kf})\end{array}$ & $\begin{array}{c}\text { OPEX } \\
\text { savings } \\
(\mathrm{kf})\end{array}$ & $\begin{array}{c}\text { Carbon } \\
\text { savings } \\
\left(\mathrm{CCO}_{2} \mathrm{e}\right)\end{array}$ & $\begin{array}{c}\text { Payback } \\
\text { time } \\
(\text { years })\end{array}$ \\
\hline 1 & Medium & 0.241 & 0.170 & 413 & 50 & 641 & 8.3 \\
\hline 2 & Small & 0.074 & 0.069 & 204 & 19 & 323 & 10.8 \\
\hline 3 & Small & 0.111 & - & 238 & 22 & 266 & 10.9 \\
\hline 4 & Medium & - & 1.035 & 133 & 45 & 218 & 3.0 \\
\hline 5 & Large & - & 1.832 & 235 & 61 & 206 & 3.9 \\
\hline 6 & Large & - & 0.674 & 86 & 19 & 167 & 4.5 \\
\hline 7 & Large & - & 0.766 & 98 & 23 & 141 & 4.3 \\
\hline 8 & Large & - & 1.059 & 136 & 33 & 126 & 4.1 \\
\hline 9 & Large & - & 0.945 & 121 & 27 & 95 & 4.4 \\
\hline 10 & Medium & - & 0.463 & 59 & 13 & 82 & 4.7 \\
\hline TOTAL & & 0.426 & 3.087 & 1,717 & 312 & 2,265 & \\
\hline
\end{tabular}

Results suggest investing in stores with relatively high payback times first (between 8 to 11 years), despite more attractive paybacks being possible elsewhere. This is because the model accounts for the time value of carbon, favouring high carbon savings early on to maximise the carbon abatement potential from installing CHP engines and PV systems.

\section{Discussion of results}

This section of the paper analyses the installed capacity of each technology over time, drawing comparisons between scenarios. The design differences are quantified by obtaining the mean standard deviation, with results plotted as histograms to visualise the number of stores where the investment strategies align, see Figure 10. The analysis includes uncertainties in model inputs, limitations of the regression model as well as the cost associated with the computing power required to solve the data intensive MILP problem.

\subsection{CHP engine installation}

Figure 10 shows the mean standard deviation between CHP engine installations in different scenarios is $43 \mathrm{~kW}_{\mathrm{e}}$, with more than half of stores following similar pathways, within a maximum standard deviation of $40 \mathrm{~kW}_{\mathrm{e}}$. It is worth noting that CHP engine sizes are not continuous, and in practice the sizes suggested by the investment strategies must be rounded to the closest commercially available size. If the mean standard deviation between scenarios is less than the average size difference between available CHP units (see Appendix A.1), it is assumed the strategies are equivalent. However, for the 3 outliers with a standard deviation greater than 100, decision-makers should investigate these stores more closely before investing, as they will be highly sensitive to changing external factors. 


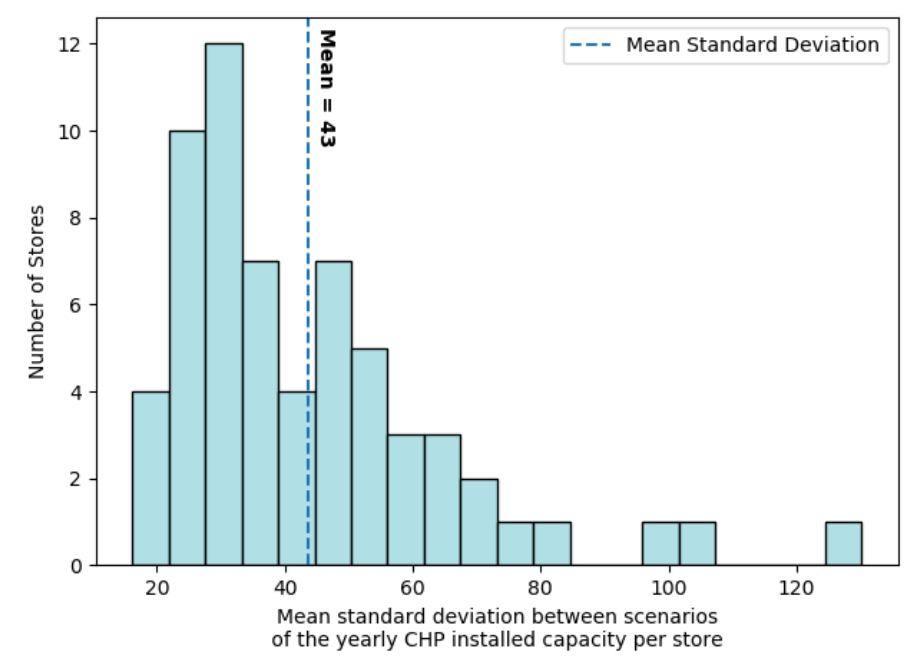

Figure 10. Histogram and mean standard deviation of the CHP engine installed capacity among investment strategies.

\subsection{PV system installation}

The discrepancies in PV installed capacity are larger than for CHP engines, with a mean standard deviation of $64 \mathrm{~kW}_{\mathrm{p}}$. However, this is less of an issue due to the modular nature of PV technology, making altering the installed capacity more straightforward. For instance, if a decision-maker invests in a non-optimal solution, the number of PV panels can be adjusted as required, however CHP engines would require a retrofit and represent a considerable additional cost.

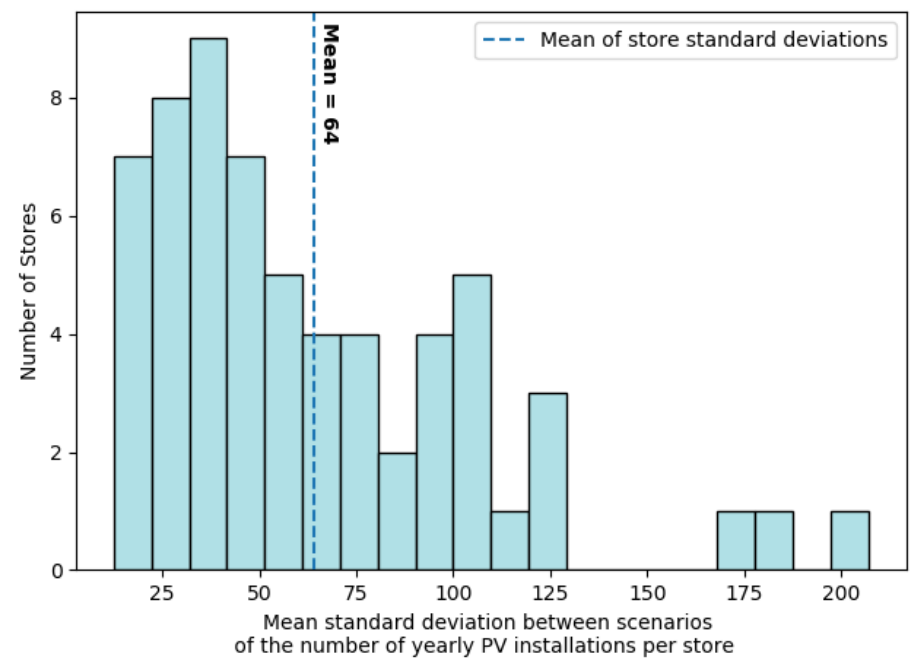

Figure 11. Histogram and mean standard deviation of the PV system installed capacity among investment strategies.

\subsection{Contrasting scenarios}

As discussed in Section 3, various energy future scenarios were considered till 2050, to assess the feasibility of meeting science-based targets in a dynamic and evolving energy sector. Table 6 provides an overview of the key results for each scenario assessed and discussed in Section 3.4. The "Two Degrees" scenario led to the greatest emissions reduction, indicating an average annual spend of $£ 2.69$ million, with an average 2.02 years payback time. This enables technology installation in all 60 stores considered, and both 2030 and 2050 science-based targets are met. For the other scenarios considered, results indicate that although investment levels are similar, the techno-economic factors such as OPEX and carbon savings deviate considerably. 
Table 6: Key techno-economic results across the scenarios considered for the investment impacting the property portfolio of 60 supermarkets.

\begin{tabular}{|c|c|c|c|c|c|c|}
\hline Scenario & $\begin{array}{c}\text { Total } \\
\text { CAPEX } \\
(\mathrm{m} £)\end{array}$ & $\begin{array}{c}\text { Total Opex } \\
\text { Savings } \\
(\mathrm{m} £)\end{array}$ & $\begin{array}{c}\text { Total Carbon } \\
\text { Savings } \\
\left(\mathrm{ktCO}_{2} \mathrm{e}\right)\end{array}$ & $\begin{array}{c}\text { Average } \\
\text { Payback } \\
\text { Time (years) }\end{array}$ & $\begin{array}{c}2030 \\
\text { Targets }\end{array}$ & $\begin{array}{c}2050 \\
\text { Targets }\end{array}$ \\
\hline Two Degrees & 80.65 & 683.00 & 517.848 & 2.02 & $\checkmark$ & $\checkmark$ \\
\hline $\begin{array}{c}\text { Slow } \\
\text { Progression }\end{array}$ & 76.15 & 517.03 & 669.811 & 2.36 & $\checkmark$ & $\checkmark$ \\
\hline Steady State & 69.35 & 331.77 & 715.311 & 3.13 & $\checkmark$ & $\mathbf{X}$ \\
\hline $\begin{array}{c}\text { Consumer } \\
\text { Power }\end{array}$ & 57.35 & 197.09 & 461.817 & 4.46 & $\checkmark$ & $\mathbf{X}$ \\
\hline
\end{tabular}

The depth of information contained in the simulation results allows spatial and temporally explicit figures and charts. Representing this information in a simple yet attractive format allows decisionmakers to comprehend the key findings from a highly complex problem. Figure 12 gives an example of how data can be represented if a dashboard is customised for decision-makers; results refer to the "Steady State" scenario presented in Section 3.7.
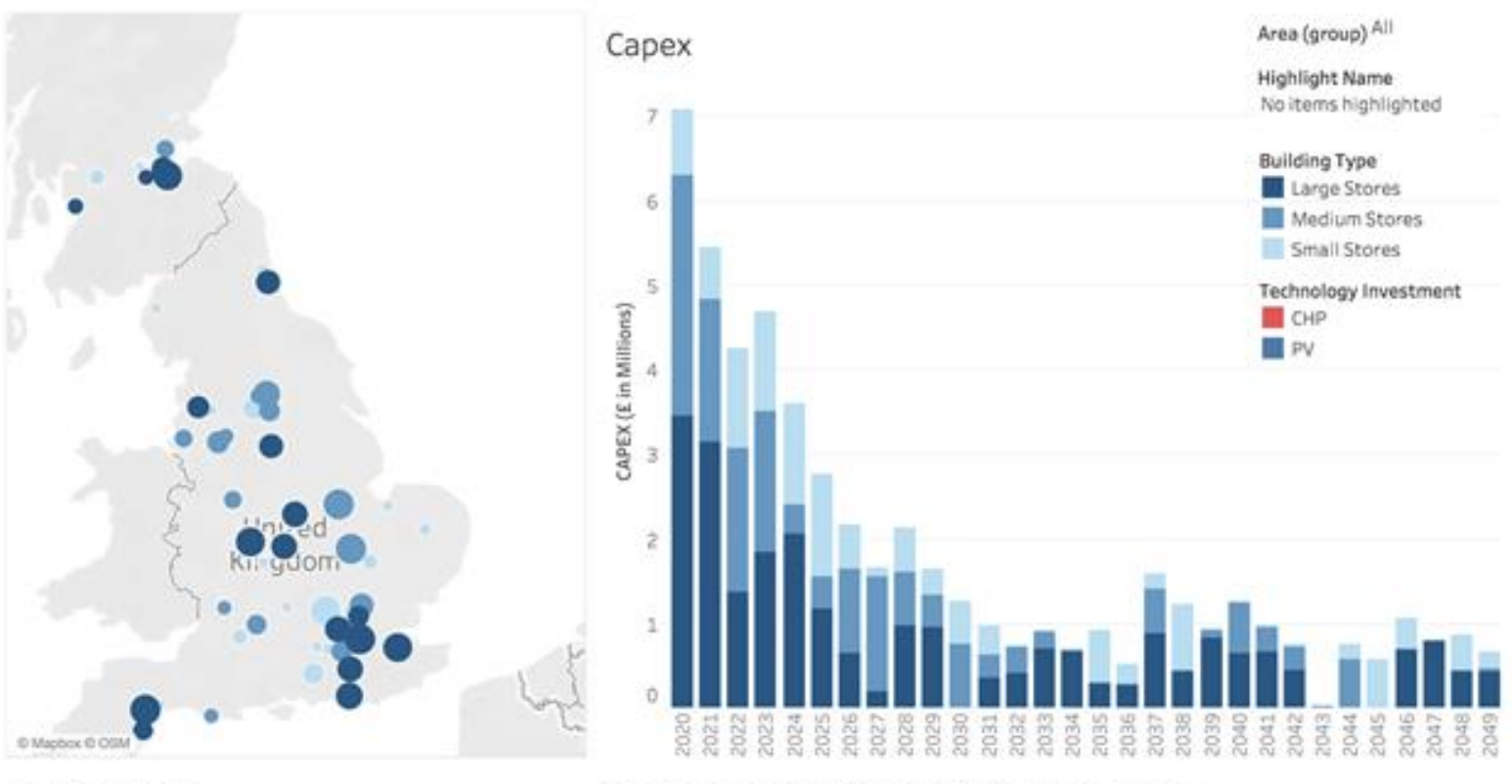

Payback time
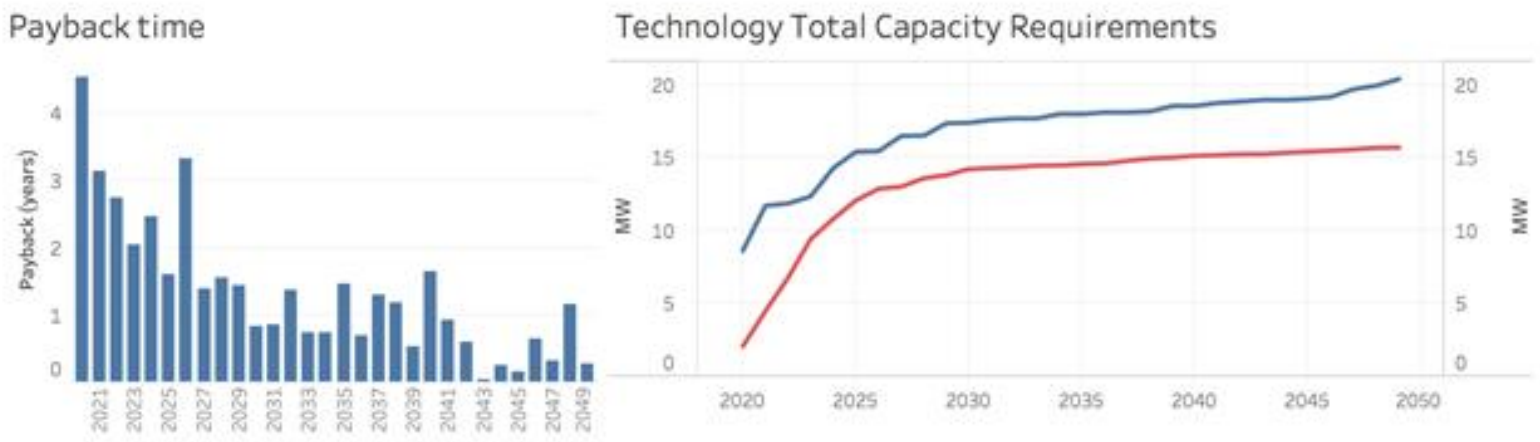

Figure 12. Graphical dashboard to represent and visualise KPIs from the "Steady-State" scenario investment programme.

\subsection{Uncertainties of model inputs}

The model outputs depend strongly on the assumptions made with regards to future changes in energy prices, grid carbon factors and technology costs. Naturally, the deterministic nature of this data is uncertain but nonetheless proves the model can offer valuable insights. This uncertainty could be 
limited by applying the strategy for a reduced time window, and then re-running the optimisation on a periodical basis (e.g. 5 years) once there is more certainty on key parameters; hence, adjusting the strategy to the energy context being faced. Another alternative would be to modify the model and undertake a classic stochastic optimisation approach to address the uncertainties an unpredictable future brings to decision-makers. Also, costs for expensive replacement of technologies after their useful life (e.g. 20 years) should be implemented in the model to increase the accuracy of the results.

In this work, it is also acknowledged that the model is limited by the technologies considered in the study. The range of technologies used as inputs for the model is for the moment limited to CHP engines and PV panels. As mentioned previously, this is because they are both proven technologies with a good track record, and for the sake of simplicity and length, more technology options were not considered [56]. This reduced choice of technology is a limitation which can be remedied by expanding on the technology options by finding the relevant data and adding them to the model. For example, alternatives such as heat recovery systems [14], thermal storage systems [25], fuel cell CHP systems [57] and dynamic energy management capabilities through advanced control systems [58], [59] are just a few examples of initiatives that could be considered by a multi-site property owner after these become more commonplace across the built environment. An additional uncertainty comes from the assumptions made for the technology costs and efficiencies that require periodical updates to ensure alignment with changing market conditions, for which we encourage a periodical review of these datasets.

\subsection{Regression limitations}

As mentioned in the regression method (Section 2.4), the calculated data for OPEX and carbon reduction do not behave linearly with respect to technology size, however linear regression was used to approximate this data. Firstly, it was assumed that the technology sizes are continuous, however in reality only a discrete number of CHP engines with their respective power capacities are available on the market. Additionally, PV technology is a modular technology which provides a total power capacity depending on the number of panels installed, a measure which is not continuous. Using the MARS analysis to divide the set of data in domains reduced the error, however this is not reduced entirely and still has an impact (especially for the carbon savings calculation). Nevertheless, the optimal solutions are indicative and are valuable as they inform decision-makers if the direction of travel with regards to carbon mitigation makes sense and is feasible to meet science-based targets. As further work to improve accuracy of results, it is suggested to approximate the CHP capex with a piecewise linear regression.

\subsection{Computational cost}

For the case study presented in this work, the model has been tested for a range of 60 supermarkets and calculates yearly investments and savings for the next 30 years. Due to the amount of data that needs to be processed it makes this method computationally intensive and time consuming, although it's executed in a computer cluster with high processing power. Results require about 7 hours to determine each scenario assessed. Therefore, optimising the modelling framework to reduce computational resources would be most valuable, otherwise such method would be quite lengthy and expensive to undertake when applied in greater detail for industries with even larger property portfolios.

\section{Conclusion}

To be in line with the decarbonisation approach suggested by science-based targets, businesses are keen to reduce their operational carbon footprint aligning their environmental targets with the Paris Climate Accord. This work has presented a method to develop an innovative decarbonisation investment strategy framework for carbon intensive industries by using statistical analysis and optimisation modelling, deviating from conventional MAC curve analysis. To the best of our knowledge this is the first concerted academic effort in modelling robust optimisation investment strategies aligned to Science Based Targets.

The example highlighted in this work concentrated on addressing food retail buildings' emissions by analysing the effect of installing low-carbon technologies, namely biomethane CHP engines and PV systems. The techno-economic impacts of these installations are showcased but the complexities regarding physical and commercial limitations have been approximated and should be detailed in future work. The 
valuable contribution from the methodology proposed here creates a detailed annual investment strategy to decarbonise business operations while maximising financial savings. The decarbonisation strategy outlines where, when, and what technology to add in each property. The method is tested by simulating the operation of a range of CHP engines and PV systems across 60 supermarkets to calculate the resulting CAPEX, OPEX and carbon reduction from 2020 to 2050 (under various future scenarios).

Results indicate that ambitious environmental milestones are feasible by 2030 if there is enough biomethane available, with estimated carbon savings ranging from $15,000 \mathrm{tCO}_{2} \mathrm{e}$ to $24,000 \mathrm{tCO}_{2} \mathrm{e}$ per year. However, depending on the changing conditions of the energy market by 2050 it is not guaranteed carbon reduction targets can be met, as factors such as public policy, energy prices and technology developments can impact the carbon footprint trajectory of the multi-site organisation. Nonetheless, the annual technology investments (ranging from $£ 1.9-£ 2.7$ million) show they also have attractive financial returns with low average payback periods ranging from 2 to 4.5 years, depending on the scenario assessed. This illustrates that businesses can make sound investments and contribute to tackle climate change. Overall, the results suggest a CAPEX ranging from $£ 57$ - $£ 80$ million is required to deliver an ambitious decarbonisation plan, while OPEX and carbon savings benefits range between $£ 197$ and $£ 683$ million and 461-715 $\mathrm{ktCO}_{2} \mathrm{e}$; respectively. The case study highlights that although carbon targets can be achieved by 2030 , the 2050 targets are more challenging to meet; suggesting additional technologies and policies should be considered and implemented. The framework serves as a blueprint of how modelling can assist decision-makers in reducing their carbon footprint cost-effectively to reach Science Based Targets. We encourage energy intensive organisations with hundreds or thousands of properties to develop a strategic holistic approach towards decarbonising their estate.

With regards to future work, aside from increasing low carbon energy sourcing alternatives and more distributed technology options, a wider range of buildings should be investigated to understand the types of solutions suitable in sites with distinct energy requirements. However, it must be noted that powerful computing processing power is required if many buildings or thorough detail is to be analysed. The model could also be enhanced by incorporating additional constraints that decision-makers regularly use before making an investment decision, for example, maximum acceptable investment payback or a preferred return on investment thresholds.

\section{Acknowledgements}

This research was supported by funds provided via the Imperial College London - Sainsbury's Supermarkets Ltd partnership.

\section{Appendices}

\section{Appendix A. Technologies}

A.1. CHP engine technologies

Table A.1: Types of CHP engine

\begin{tabular}{ccccc}
\hline $\begin{array}{c}\text { CHP unit name } \\
\text { and size }\left(\mathrm{kW}_{\mathrm{e}}\right)\end{array}$ & $\begin{array}{c}\text { Capital cost } \\
(\mathrm{k} f)\end{array}$ & $\begin{array}{c}\text { Electrical } \\
\text { Efficiency }(\%)\end{array}$ & $\begin{array}{c}\text { Thermal } \\
\text { Efficiency }(\%)\end{array}$ & $\begin{array}{c}\text { Heat Output } \\
\left(\mathrm{kW}_{\text {th }}\right)\end{array}$ \\
\hline Unit 35 & $£ 94.2$ & $30.9 \%$ & $54.9 \%$ & 62 \\
Unit 50 & $£ 115$ & $34.0 \%$ & $53.3 \%$ & 79 \\
Unit 90 & $£ 159$ & $32.1 \%$ & $58.2 \%$ & 162 \\
Unit 100 & $£ 169$ & $32.8 \%$ & $57.4 \%$ & 174 \\
Unit 110 & $£ 178$ & $33.4 \%$ & $56.5 \%$ & 185 \\
Unit 125 & $£ 189$ & $34.2 \%$ & $55.4 \%$ & 199 \\
Unit 135 & $£ 199$ & $34.1 \%$ & $55.2 \%$ & 218 \\
Unit 150 & $£ 211$ & $35.1 \%$ & $54.6 \%$ & 234 \\
Unit 165 & $£ 223$ & $32.7 \%$ & $56.4 \%$ & 284 \\
Unit 185 & $£ 238$ & $33.6 \%$ & $56.1 \%$ & 308 \\
\hline
\end{tabular}




\begin{tabular}{ccccc}
\hline Unit 210 & $£ 255$ & $34.6 \%$ & $55.6 \%$ & 337 \\
Unit 230 & $£ 268$ & $35.3 \%$ & $55.1 \%$ & 357 \\
Unit 310 & $£ 317$ & $37.8 \%$ & $43.5 \%$ & 357 \\
Unit 375 & $£ 352$ & $38.7 \%$ & $41.0 \%$ & 399 \\
Unit 400M & $£ 367$ & $38.8 \%$ & $49.1 \%$ & 513 \\
Unit 425 & $£ 378$ & $38.5 \%$ & $41.9 \%$ & 464 \\
Unit 500 & $£ 414$ & $39.0 \%$ & $40.7 \%$ & 523 \\
Unit 530M & $£ 428$ & $39.6 \%$ & $48.3 \%$ & 648 \\
Unit E770 & $£ 527$ & $42.3 \%$ & $44.9 \%$ & 823 \\
Unit 850 & $£ 556$ & $42.8 \%$ & $44.7 \%$ & 891 \\
\hline
\end{tabular}

A.2. PV panel technologies

Table A.2: Different PV panel specifications

\begin{tabular}{cccccccc}
\hline Type & $\begin{array}{c}\text { Price per } \\
\text { Module }\end{array}$ & $\begin{array}{c}\text { Nominal } \\
\text { Power } \\
(\mathrm{Wp})\end{array}$ & $\begin{array}{c}\text { Electrical } \\
\text { Efficiency } \\
(100 \%)\end{array}$ & $\begin{array}{c}\text { CAPEX } \\
(£ / \mathrm{Wp})\end{array}$ & $\begin{array}{c}\text { Module } \\
\text { Area }\left(\mathrm{m}^{2}\right)\end{array}$ & $\begin{array}{c}\text { Module } \\
\text { Weight } \\
(\mathrm{kg})\end{array}$ & $\begin{array}{c}\text { Lifetime } \\
(\text { years })\end{array}$ \\
\hline Mono-Si & $£ 128$ & 293 & $18.07 \%$ & $£ 0.437$ & 1.65 & 19.1 & 20 \\
Poly-Si & $£ 83$ & 243 & $14.81 \%$ & $£ 0.345$ & 1.65 & 19.1 & 20 \\
CIGS & $£ 130$ & 160 & $12.60 \%$ & $£ 0.814$ & 1.3 & 13.7 & 20 \\
CdTe & $£ 63$ & 90 & $12.50 \%$ & $£ 0.703$ & 0.72 & 12.1 & 20 \\
\hline
\end{tabular}

\section{Appendix B. Results}

B.1 PV panels

Table B.1: Exhaustive list of stores for investment in the first year of the "Steady State" scenario.

\begin{tabular}{|c|c|c|c|c|c|c|c|}
\hline Store & $\begin{array}{c}\text { Building } \\
\text { Type }\end{array}$ & $\begin{array}{c}\text { CHP } \\
\text { Capacity } \\
\left(\mathrm{MW}_{\mathrm{e}}\right)\end{array}$ & $\begin{array}{c}\text { PV } \\
\text { Capacity } \\
\left(\mathrm{MW}_{\mathrm{p}}\right)\end{array}$ & $\begin{array}{c}\text { CAPEX } \\
(\mathrm{kf})\end{array}$ & $\begin{array}{c}\text { OPEX } \\
\text { savings } \\
(\mathrm{kf})\end{array}$ & $\begin{array}{c}\text { Carbon } \\
\text { savings } \\
\left(\mathrm{tCO}_{2} \mathrm{e}\right)\end{array}$ & $\begin{array}{c}\text { Payback } \\
\text { time } \\
(\text { years })\end{array}$ \\
\hline 1 & Medium & 0.241 & 0.170 & 413 & 50 & 641 & 8.3 \\
\hline 2 & Small & 0.074 & 0.069 & 204 & 19 & 323 & 10.8 \\
\hline 3 & Small & 0.111 & - & 238 & 22 & 266 & 10.9 \\
\hline 4 & Medium & - & 1.035 & 133 & 45 & 218 & 3.0 \\
\hline 5 & Large & - & 1.832 & 235 & 61 & 206 & 3.9 \\
\hline 6 & Large & - & 0.674 & 86 & 19 & 167 & 4.5 \\
\hline 7 & Large & - & 0.766 & 98 & 23 & 141 & 4.3 \\
\hline 8 & Large & - & 1.059 & 136 & 33 & 126 & 4.1 \\
\hline 9 & Large & - & 0.945 & 121 & 27 & 95 & 4.4 \\
\hline 10 & Medium & - & 0.463 & 59 & 13 & 82 & 4.7 \\
\hline 11 & Medium & - & 0.548 & 70 & 16 & 64 & 4.4 \\
\hline 12 & Medium & - & 0.503 & 64 & 13 & 60 & 5.0 \\
\hline 13 & Large & - & 0.536 & 69 & 17 & 54 & 4.0 \\
\hline 14 & Small & - & 0.302 & 39 & 9 & 41 & 4.5 \\
\hline 15 & Small & - & 0.191 & 24 & 5 & 26 & 4.5 \\
\hline 16 & Small & - & 0.175 & 22 & 5 & 24 & 4.2 \\
\hline 17 & Small & - & 0.203 & 26 & 7 & 23 & 4.0 \\
\hline
\end{tabular}




\begin{tabular}{|c|c|c|c|c|c|c|c|}
\hline 18 & Medium & - & 0.144 & 18 & 4 & 22 & 4.2 \\
\hline 19 & Medium & - & 0.182 & 23 & 5 & 22 & 4.5 \\
\hline 20 & Small & - & 0.151 & 19 & 6 & 21 & 3.5 \\
\hline 21 & Large & - & 0.155 & 20 & 5 & 18 & 3.9 \\
\hline 22 & Medium & - & 0.113 & 15 & 3 & 15 & 4.6 \\
\hline 23 & Medium & - & 0.090 & 11 & 3 & 12 & 4.0 \\
\hline 24 & Small & - & 0.094 & 12 & 3 & 9 & 3.7 \\
\hline 25 & Medium & - & 0.064 & 8 & 2 & 8 & 4.4 \\
\hline 26 & Small & - & 0.064 & 8 & 2 & 8 & 4.5 \\
\hline 27 & Small & - & 0.051 & 7 & 1 & 6 & 4.8 \\
\hline 28 & Medium & - & 0.029 & 4 & 1 & 4 & 4.0 \\
\hline 29 & Small & - & 0.015 & 2 & - & 2 & 4.0 \\
\hline 30 & Medium & - & 0.010 & 1 & - & 1 & 4.2 \\
\hline 31 & Large & - & 0.720 & 92 & 28 & - & 3.3 \\
\hline 32 & Medium & - & 0.640 & 8 & 2 & - & 4.5 \\
\hline 33 & Small & - & 0.171 & 22 & 7 & - & 3.2 \\
\hline 34 & Small & - & 0.028 & 4 & 1 & - & 4.5 \\
\hline TOTAL & & 0.426 & 7.690 & 2,295 & 458 & 2,705 & \\
\hline
\end{tabular}

\section{References}

1. United Nations Climate Change (2016). "The Paris Agreement". Available at https://unfccc.int/process-and-meetings/the-paris-agreement/the-paris-agreement. (Accessed: 4 September 2019).

2. Carbon Disclosure Project (CDP) (2020). "CDP Scores". Available at https://www.cdp.net/. (Accessed: 10 November 2019).

3. Science Based Targets. (2017). "Companies Taking Action". Available at: https://sciencebasedtargets.org/companies-taking-action/ (Accessed 8 December 2017).

4. Rissman J, Bataille C, Masanet E, Aden N, Morrow WR, Zhou N, Elliott N, Dell R, Heeren N, Huckestein B, Cresko J, Miller SA, Roy J, Fennell P, Cremmins B, Blank TK, Hone D, Williams ED, de la Rue du Can S, Sisson B, Williams M, Katzenberger J, Burtraw D, Sethi G, Ping H, Danielson D, Lu H,Lorber T,Dinkel J, Helseth J. (2020). "Technologies and policies to decarbonize global industry: Review and assessment of mitigation drivers through 2070". Applied Energy, Vol. 266, 114848. https://doi.org/10.1016/j.apenergy.2020.114848

5. Petrini M, Pozzebon M. (2009). "Managing sustainability with the support of business intelligence: Integrating socio-environmental indicators and organisational context". The Journal of Strategic Information Systems, Vol. 18, Issue 4, pp. 178-191. https://doi.org/10.1016/j.jsis.2009.06.001

6. Mendicino L, Menniti D, Pinnarelli A, Sorrentino N. (2019). "Corporate power purchase agreement: Formulation of the related levelized cost of energy and its application to a real life case study". Applied Energy, Vol 253, 113577. https://doi.org/10.1016/j.apenergy.2019.113577

7. RE100 (2015). Available at http://www.there100.org/ (Accessed 17 October 2019)

8. Darling SB, You F, Veselka T, Velosa A. (2011). "Assumptions and the levelized cost of energy for photovoltaics". Energy \& Environmental Science, Vol. 4, pp. 3133-3139. https://doi.org/10.1039/C0EE00698J

9. Acha S, Le Brun N, Damaskou M, Fubara TC, Mulgundmath V, Markides CN, Shah N. (2020). "Fuel cells as combined heat and power systems in commercial buildings: A case study in the foodretail sector". Energy, pp. 118046. https://doi.org/10.1016/j.energy.2020.118046

10. IGD (2019). "UK food sales to grow by $£ 24 \mathrm{bn}$ by $2024 "$. Available at https://www.igd.com/articles/article-viewer/t/uk-food-sales-to-grow-by-24bn-by-2024/i/21868. (Accessed: 31 July 2019). 
11. Tassou SA, Kolokotroni M, Gowreesunker B, Stojceska V, Azapagic A, Fryer P, Bakalis S. (2014). "Energy demand and reduction opportunities in the UK food chain". Proceedings of the Institution of Civil Engineers - Energy, Vol. 167, Issue 3, pp. 162-170. https://doi.org/10.1680/ener.14.00014

12. Caritte V, Acha S, Shah N. (2015). "Enhancing Corporate Environmental Performance Through Reporting and Roadmaps". Business Strategy and the Environment, Volume 24, Issue 5, pp. 289308. https://doi.org/10.1002/bse. 1818

13. Wm Morrison Supermarkets PLC (2020). "Corporate Responsibility Report 2019/20". Available at https://www.morrisons-corporate.com/cr/corporate-responsibility/ (Accessed 7 April 2020).

14. Sarabia EJ, Acha S, Le Brun N, Soto V, Pinazo JM, Markides CN, Shah N. (2019). "Modelling of a real $\mathrm{CO} 2$ booster installation and evaluation of control strategies for heat recovery applications in supermarkets." International Journal of Refrigeration. Vol. 107, pp. 288-300. https://doi.org/10.1016/j.ijrefrig.2019.08.005

15. Acha S, Du Y, Shah N. (2016). "Enhancing Energy Efficiency in Supermarket Refrigeration Systems through a Robust Energy Performance Indicator." International Journal of Refrigeration, Vol. 64, pp. 40-50. https://doi.org/10.1016/j.ijrefrig.2015.12.003

16. Hart M, Austin W, Acha S, Le Brun N, Markides CN, Shah N. (2020). "A roadmap investment strategy to reduce carbon intensive refrigerants in the food retail industry." Journal of Cleaner Production, Vol. 275, pp. 123039. https://doi.org/10.1016/j.jclepro.2020.123039

17. Langshaw L, Ainalis D, Acha S, Shah N, Stettler M. (2020). "Environmental and economic analysis of liquefied natural gas (LNG) for heavy goods vehicles in the UK: A Well-to-Wheel and total cost of ownership evaluation." Energy Policy, Vol. 137, 111161. https://doi.org/10.1016/j.enpol.2019.111161

18. Naidoo M, Gasparatos A. (2018). "Corporate environmental sustainability in the retail sector: Drivers, strategies and performance measurement." Journal of Cleaner Production, Vol. 203, pp. 125-142. https://doi.org/10.1016/j.jclepro.2018.08.253

19. Moretto A, Macchion L, Lion A, Caniato F, Danese P, Vinelli A. (2018). "Designing a roadmap towards a sustainable supply chain: A focus on the fashion industry." Journal of Cleaner Production, Vol. 193, pp. 125-142. https://doi.org/10.1016/j.jclepro.2018.04.273

20. Tang S, Demeritt D. (2018). "Climate Change and Mandatory Carbon Reporting: Impacts on Business Process and Performance". Business Strategy and the Environment, Volume 27, Issue 4, pp. 437-455. https://doi.org/10.1002/bse.1985

21. Kesicki F, Ekins P. (2012). "Marginal abatement cost curves: a call for caution." Climate Policy, Vol. 12, Issue 2, pp. 219-236. https://doi.org/10.1080/14693062.2011.582347

22. Spyrou M, Shanks K, Cook MJ, Pitcher J, Lee R. (2014). "An empirical study of electricity and gas demand drivers in large food retail buildings of a national organisation." Energy and Buildings, Vol. 68, Part A, pp. 172-182. https://doi.org/10.1016/j.enbuild.2013.09.015

23. Braun MR, Altan H, Beck SBM. (2014). "Using regression analysis to predict the future energy consumption of a supermarket in the UK." Applied Energy, Vol. 130, pp. 305-313. https://doi.org/10.1016/j.apenergy.2014.05.062

24. Polzot A, D’Agaro P, Paride G, Cortella G. (2016). "Modelling commercial refrigeration systems coupled with water storage to improve energy efficiency and perform heat recovery." International Journal of Refrigeration, Vol. 69, pp. 313-323. https://doi.org/10.1016/j.ijrefrig.2016.06.012

25. Maouris G, Sarabia EJ, Acha S, Shah N, Markides CN. (2020). "CO2 refrigeration system heat recovery and thermal storage modelling for space heating provision in supermarkets: An integrated approach." Applied Energy, Vol. 264, 114722. https://doi.org/10.1016/j.apenergy.2020.114722

26. Mylona Z, Kololotroni M, Tassou SA. (2017). "Frozen food retail: Measuring and modelling energy use and space environmental systems in an operational supermarket." Energy and Buildings, Vol. 144, pp.172-182. https://doi.org/10.1016/j.enbuild.2017.03.049

27. Efstratiadi M, Acha S, Shah N, Markides CN. (2019). "Analysis of a closed-loop water-cooled refrigeration system in the food retail industry: A UK case study”. Energy, Vol. 174, pp. 11331144. https://doi.org/10.1016/j.energy.2019.03.004

28. Mavromatidis G, Acha S, Shah N. (2013). "Diagnostic tools of energy performance for supermarkets using Artificial Neural Network algorithms." Energy and Buildings, Vol. 62, pp. 304-314. https://doi.org/10.1016/j.enbuild.2017.03.049 
29. Ruparathna R, Hewage K, Sadiq R. (2016). "Improving the energy efficiency of the existing building stock: A critical review of commercial and institutional buildings." Renewable and Sustainable Energy Reviews, Vol. 53, pp. 1032-1045. https://doi.org/10.1016/j.rser.2015.09.084

30. Liu P, Pistikopoulos EN, Li Z. (2010). "An energy systems engineering approach to the optimal design of energy systems in commercial buildings.” Energy Policy, Vol. 38, pp. 4224-4231. https://doi.org/10.1016/j.enpol.2013.05.009

31. Acha S, Mariaud A, Shah N, Markides CN. (2018). "Optimal design and operation of distributed low-carbon energy technologies in commercial buildings". Energy, Vol 142, pp. 578-591, https://doi.org/10.1016/j.energy.2017.10.066

32. Suamir IN, Tassou SA. (2013). "Performance evaluation of integrated trigeneration and CO2 refrigeration systems." Applied Thermal Engineering, Vol. 50, pp. 1487-1495, https://doi.org/10.1016/j.applthermaleng.2011.11.055

33. Cedillos D, Acha S, Shah N, Markides CN. (2016). "A Technology Selection and Operation (TSO) optimisation model for distributed energy systems: Mathematical formulation and case study." Applied Energy, Vol. 180, pp. 491-503, https://doi.org/10.1016/j.apenergy.2016.08.013

34. Mariaud A, Acha S, Ekins-Daukes N, Shah N, Markides CN. (2017). "Integrated optimisation of photovoltaic and battery storage systems for UK commercial buildings." Applied Energy, Vol. 199, pp. 466-478, https://doi.org/10.1016/j.apenergy.2017.04.067

35. Sorrentino A, Pantaleo AM, Le Brun N, Acha S, Markides CN, Braccio G, Fanelli E, Camporeale SM. (2018). "Energy performance and profitability of biomass boilers in the commercial sector: A case study in the UK." Energy Procedia, Vol. 148, pp. 639-646. https://doi.org/10.1016/j.egypro.2018.08.152

36. Allan G, Eromenko I, Gilmartin M, Kockar I, McGregor P. (2015). "The economics of distributed energy generation: A literature review." Renewable and Sustainable Energy Reviews, Vol. 42, pp. 543-556. https://doi.org/10.1016/j.rser.2014.07.064

37. Capros P, Paroussos L, Fragkos P, Tsani S, Boitier B, Wagner F, Busch S, Resch G, Blesl M, Bollen J. (2014). "European decarbonisation pathways under alternative technological and policy choices: A multi-model analysis.” Energy Strategy Reviews, Vol. 2, Issue 3-4, pp. 231-245. https://doi.org/10.1016/j.esr.2013.12.007

38. Fais B, Keppo I, Zeyringer M, Usher W, Daly H. (2016). "Impact of technology uncertainty on future low-carbon pathways in the UK." Energy Strategy Reviews, Vol. 13-14, pp. 154-168. https://doi.org/10.1016/j.esr.2016.09.005

39. Usher W, Strachan N. (2012). "Critical mid-term uncertainties in long-term decarbonisation pathways." Energy Policy, Vol. 41, pp. 433-444. https://doi.org/10.1016/j.enpol.2011.11.004

40. Bentley Y. (2016). "UK company strategies in reducing carbon dioxide emissions." International Journal of Business and Economic Development, Vol. 4, No. 2, pp. 200-207. http://hdl.handle.net/10547/621918

41. Ioannis I, Xin Li S, Serafeim G. (2016). "The Effect of Target Difficulty on Target Completion: The Case of Reducing Carbon Emissions." The Accounting Review, Vol. 91, Issue 5, pp. 14671492. https://doi.org/10.2308/accr-51307

42. Balcombe P, Rigby D, Azapagic A. (2015). "Energy self-sufficiency, grid demand variability and consumer costs: Integrating solar PV, Stirling engine CHP and battery storage." Applied Energy, Vol. 155, pp. 393-408. https://doi.org/10.1016/j.apenergy.2015.06.017

43. Amazon (2020). "Reaching Net Zero Carbon by 2040". Available at https://sustainability.aboutamazon.com/ (Accessed: 4 June 2020).

44. Microsoft (2020). "Microsoft will be carbon negative by 2030". Available at https://blogs.microsoft.com/blog/2020/01/16/microsoft-will-be-carbon-negative-by-

2030/\#: : :text=By\%202030\%20Microsoft\%20will\%20be,goal\%20but\%20a\%20detailed\%20plan (Accessed: 25 June 2020).

45. Sainsbury's (2020). "Net Zero". https://www.about.sainsburys.co.uk/making-a-difference/netzero (Accessed: 8 May 2020).

46. Carbon Disclosure Project (CDP) (2020). "Walmart's Science Based Target: A Game Changer". Available at https://www.cdp.net/en/articles/climate/walmarts-science-based-target-a-gamechanger (Accessed: 10 June 2020). 
47. Kolokotsa D, Rovas D, Kosmatopoulos E, Kalaitzakis K. (2011). "A roadmap towards intelligent net zero- and positive-energy buildings." Solar Energy, Vol. 85, pp. 3067-3084. https://doi.org/10.1016/j.solener.2010.09.001

48. Mundada AS, Shah KK, Pearce JM. (2016). "Levelized cost of electricity for solar photovoltaic, battery and cogen hybrid systems." Renewable and Sustainable Energy Reviews, Vol. 57, pp. 692703. https://doi.org/10.1016/j.rser.2015.12.084

49. National Grid. (2019). Future Energy Scenarios. [Online] Available at: http://fes.nationalgrid.com/ [Accessed 28 September 2019].

50. Met Office Integrated Data Archive System (MIDAS) Land and Marine Surface Stations Data. Available at: https://catalogue.ceda.ac.uk/uuid/1e040656ae0a4646acafbef6144b10f2 [accessed 18 February 2020].

51. Ofgem. (2018). About the FIT scheme. [Online] Available at: https://www.ofgem.gov.uk/environmental-programmes/fit/about-fit-scheme [Accessed 14 May 2018].

52. UK Government BEIS (2019). Enhanced Capital Allowance scheme for energy-saving technologies. [Online] Available: https://www.gov.uk/government/publications/enhanced-capitalallowance-scheme-for-energy-saving-technologies [Accessed 18 February 2020].

53. UK Government BEIS. (2018). Greenhouse gas reporting: conversion factors 2018. [Online] Available at: https://www.gov.uk/government/publications/greenhouse-gas-reporting-conversionfactors-2018 [Accessed 18 May 2018].

54. Speirs J, Balcombe P, Johnson E, Martin J, Brandon N, Hawkes A. (2016). "A greener gas grid: What are the options." Energy Policy, Vol. 118, pp. 291-297. https://doi.org/10.1016/j.enpol.2018.03.069

55. UK Government (2019). UK becomes first major economy to pass net zero emissions la. [Online] available at: https://greengb.campaign.gov.uk/ [Accessed 11 April2020].

56. Ayoub AN, Gaigneux A, Le Brun N, Acha S, Lambert R, Shah N. (2019). "The development of a carbon roadmap investment strategy for carbon intensive food retail industries." Energy Procedia, Vol. 161, pp. 333-342. https://doi.org/10.1016/j.egypro.2019.02.107

57. Acha S, Le Brun N, Damaskou M, Fubara TC, Mulgundmath V, Markides CN, Shah N. (2020). "Fuel cells as combined heat and power systems in commercial buildings: A case study in the foodretail sector". Energy, Vol 206, pp. 118046. https://doi.org/10.1016/j.energy.2017.10.066

58. Olympios AV, Le Brun N, Acha S, Shah N, Markides CN. (2020). "Stochastic real-time operation control of a combined heat and power (CHP) system under uncertainty". Energy Conversion and Management, Vol 216, pp. 112916. https://doi.org/10.1016/j.enconman.2020.112916

59. Gonzato S, Chimento J, O’Dwyer E, Bustos-Turu G, Acha S, Shah N. (2019). "Hierarchical price coordination of heat pumps in a building network controlled using model predictive control." Energy and Buildings. Vol. 202, pp. 109421. https://doi.org/10.1016/j.enbuild.2019.109421

60. Howard B, Acha S, Shah N, Polak J. (2019). "Implicit Sensing of Building Occupancy Count with Information and Communication Technology Data Sets." Building and Environment. Vol. 157, pp. 297-308. https://doi.org/10.1016/j.buildenv.2019.04.015

61. Almeida M, Ferreira M. (2018). "Ten questions concerning cost-effective energy and carbon emissions optimization in building renovation." Building and Environment. Vol. 143, pp. 15-23. https://doi.org/10.1016/j.buildenv.2018.06.036

62. Pan W, Li K. (2016). "Clusters and exemplars of buildings towards zero carbon.” Building and Environment. Vol. 104, pp. 92-101. https://doi.org/10.1016/j.buildenv.2016.04.027

63. Zheng L, Lai J. (2018). "Environmental and economic evaluations of building energy retrofits: Case study of a commercial building." Building and Environment. Vol. 145, pp. 14-23. https://doi.org/10.1016/j.buildenv.2018.09.007 